UCRL-CR-129411

S/C - B317385

\title{
The Project Progress Report
}

\author{
A. I. Isakov \\ Russian Academy of Sciences
}

December 31, 1997

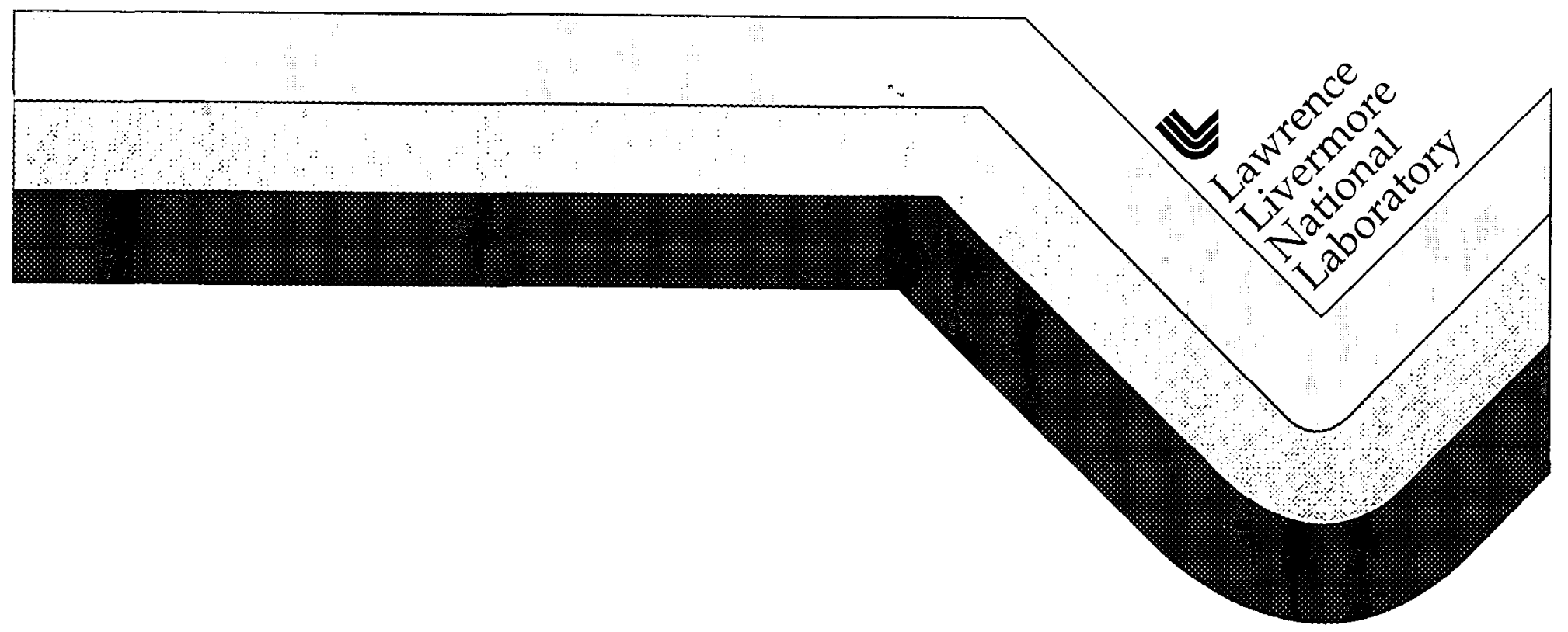




\section{DISCLAIMER}

This document was prepared as an account of work sponsored by an agency of the United States Government. Neither the United States Government nor the University of California nor any of their employees, makes any warranty, express or implied, or assumes any legal liability or responsibility for the accuracy, completeness, or usefulness of any information, apparatus, product, or process disclosed, or represents that its use would not infringe privately owned rights. Reference herein to any specific commercial product, process, or service by trade name, trademark, manufacturer, or otherwise, does not necessarily constitute or imply its endorsement, recommendation, or favoring by the United States Government or the University of California. The views and opinions of authors expressed herein do not necessarily state or reflect those of the United States Government or the University of California, and shall not be used for advertising or product endorsement purposes.

This report has been reproduced directly from the best available copy.

Available to DOE and DOE contractors from the Office of Scientific and Technical Information P.O. Box 62, Oak Ridge, TN 37831

Prices available from (615) 576-8401, FTS 626-8401

Available to the public from the National Technical Information Service

U.S. Department of Commerce 5285 Port Royal Rd., Springfield, VA 22161

Work performed under the auspices of the U.S. Department of Energy by Lawrence Livermore National Laboratory under Contract W-7405-ENG-48. 
Russian Academy of Sciences

P. N. Lebedev Physical Institute

Department of Neutron Physics

Thermonuclear Target Laboratory

\section{The Fourth (XII) Quarter Report}

This report was carried out by contract with

Lawrence Livermore National Laboratory.

Master Task Agreement Number B239618

Task Order Number B317385.

Moscow. Russia.

1997. 


\section{LIST OF PROJECT PARTICIPANTS.}

1. Supervisor - deputy director

2. Head investigator - head of lab. Investigators

3. Researcher

4. Researcher

5. Researcher

6. Group leader

7. Group leader

8. Group leader

9. Group leader

10. Researcher

11. Researcher

12. Engineer
Prof. A.I. Isakov. dr. Yu.A.Merkuliev.

A.A.Akunets.

dr. D. Alikperov.

dr. N.G.Borisenko.

dr. A.I. Gromov.

dr. V.M.Dorogotovtsev. dr. A.I.Nikitenko. dr. S.A. Startsev.

dr. S.M.Tolokonnikov. A.P. Turivnoy.

T. V. Chernyavskaya. 


\section{INTRODUCTION.}

According to the three-year program investigating of the large polystyrene shells fabrication technology and of designing Ballistic furnace Master Task Agreement N B239618, signed February 25, 1993, and Task Order N B317385, signed October 10, 1995, and Modification Number 01 to MTS, signed September 3, 1996, and Modification Number 02, signed October 23, 1997, during fourth (twelfth) quarter of contract Laboratory of Thermonuclear Target (TTL) of Department of Neutron Physics (DNP) of Lebedev Physical Institute has fulfilled works of two variety: first, research of polystyrene shells formation conditions in drop tower furnace and ballistic furnace; second, creation of computer codes for simulation of shells formation processes, including numerous nucleation. Besides that polystyrene shells with diameter up to $2 \mathrm{~mm}$ transmitted to LLNL in parcel.

At $12^{\text {th }}$ quarter we paid serious attention to careful experiments with larger initial granules. We used in those experiments $0.7-0.8-\mathrm{mm}$ granules with narrow size distribution. Each granule fractions was carefully examined and characterized just before experiment. Many shells' formation experiments were carried out and results of these experiments were compared with theoretical calculations. But this experiments were carried out with initial granules contained 3.5\% (weight) of blowing agents (ethyl acetate, water, monomer etc.). New experiments on drop tower furnace had goal to research dependence of shell diameter from quantity of blowing agents. Besides that on drop tower furnace dependence of large (about 2mm) shell surface quality from temperature profiles were researched.

Experiments showed that large solid polymer granules, which contain easy-boiling solvent transform into foam fragments, when heated quickly. In other words, there are a lot of initial supercritical nuclei of new (gas) phase. If heating is continued then the foam is destroyed and foam fragments turn into monoshells. In one part of this work we offer a mathematical model of viscous fluid dynamics for this process, but using of model are not possible without knowledge of calculation of nucleus homogeneous and heterogeneous formation velocity. The method of calculation of nucleus homogeneous and heterogeneous formation is discussed at the abolition (foaming) of polymer with a small amount of the low-temperature boiling admixture. We take into account the influence of the non-ideal molecular mixture and the non-equilibrium chemical state of gas bubbles. Calculation results agree satisfactory with experimental data, obtained in our experiments.

At $12^{\text {th }}$ quarter computer program improvements, which helped user introduce of physical constants and technological conditions, were carried. Besides that in model and computer codes were included new physical processes. We begin to take into account energy of boiling and energy of connection between boiling agent and polymer on surface of polymer shells. 


\section{$12^{\text {th }}$ quarter ballistic furnace progress report. A.I.Nikitenko, S.M.Tolokonnikov}

\section{Introduction.}

At $12^{\text {th }}$ quarter we paid serious attention to careful experiments with larger initial granules. We used in those experiments $0.7-0.8-\mathrm{mm}$ granules with narrow size distribution. Each granule fractions was carefully examined and characterized just before experiment. Many shells' formation experiments were carried out and results of these experiments were compared with theoretical calculations.

\section{Initial granule preparation and characterization.}

To grade initial granules to size we have made simple device based on usual optical slit adjustable for width with additional dish over the slit. Initial granules are put into the dish and under the vibration undersize granule pass through the slit and fall down into the receiver dish. Then width of the slit is decreased by 10 microns, granules from the receiver dish are put into upper dish and procedure is repeated. Granules staying in the upper dish are used for experiments.

This method is slower than usual sieving but gives us much better results. Typical granule's size distributions are presented on fig. 1 for granules graded with sieve (a) and with slit (b).

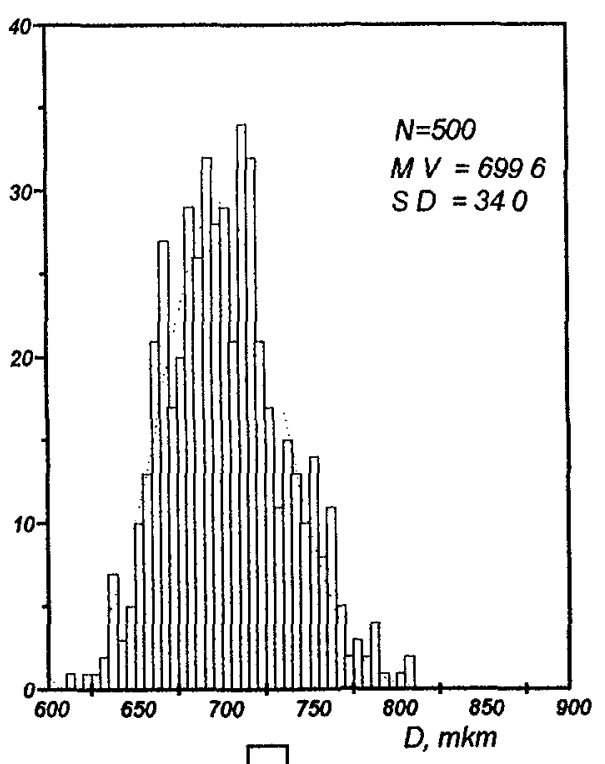

a

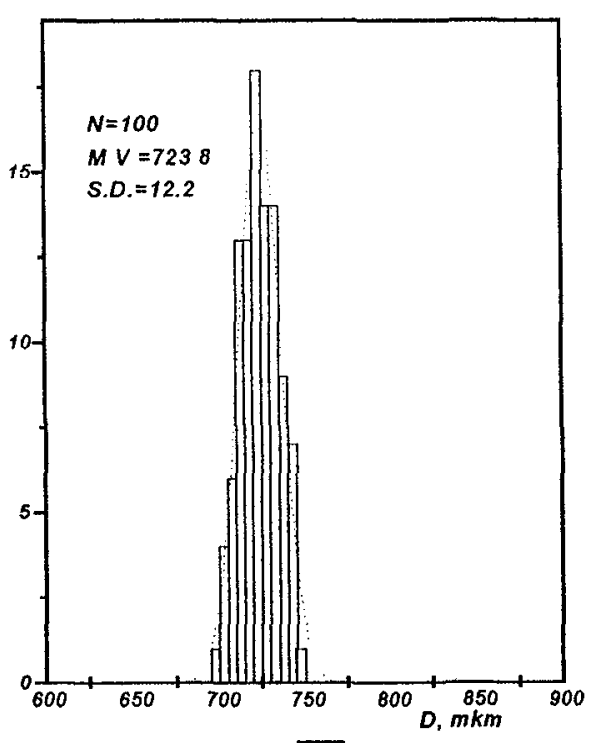

b

Fig. 1. Initial granules diameter distribution (D - diameter, M.V. -- mean value, S.D. -- standard deviation, $\mathrm{N}$ - number of measured granules, dashed line - gaussian fit). 
We had measured distributions of initial granule size at the last sets of shells' formation experiments before every experiment. These distributions are presented on fig.2. One can see from fig. 2 those distribution are quite narrow. It is important for understanding results of shells' formation experiments because of shell' formation process peculiarities strongly depend on initial granule mass.
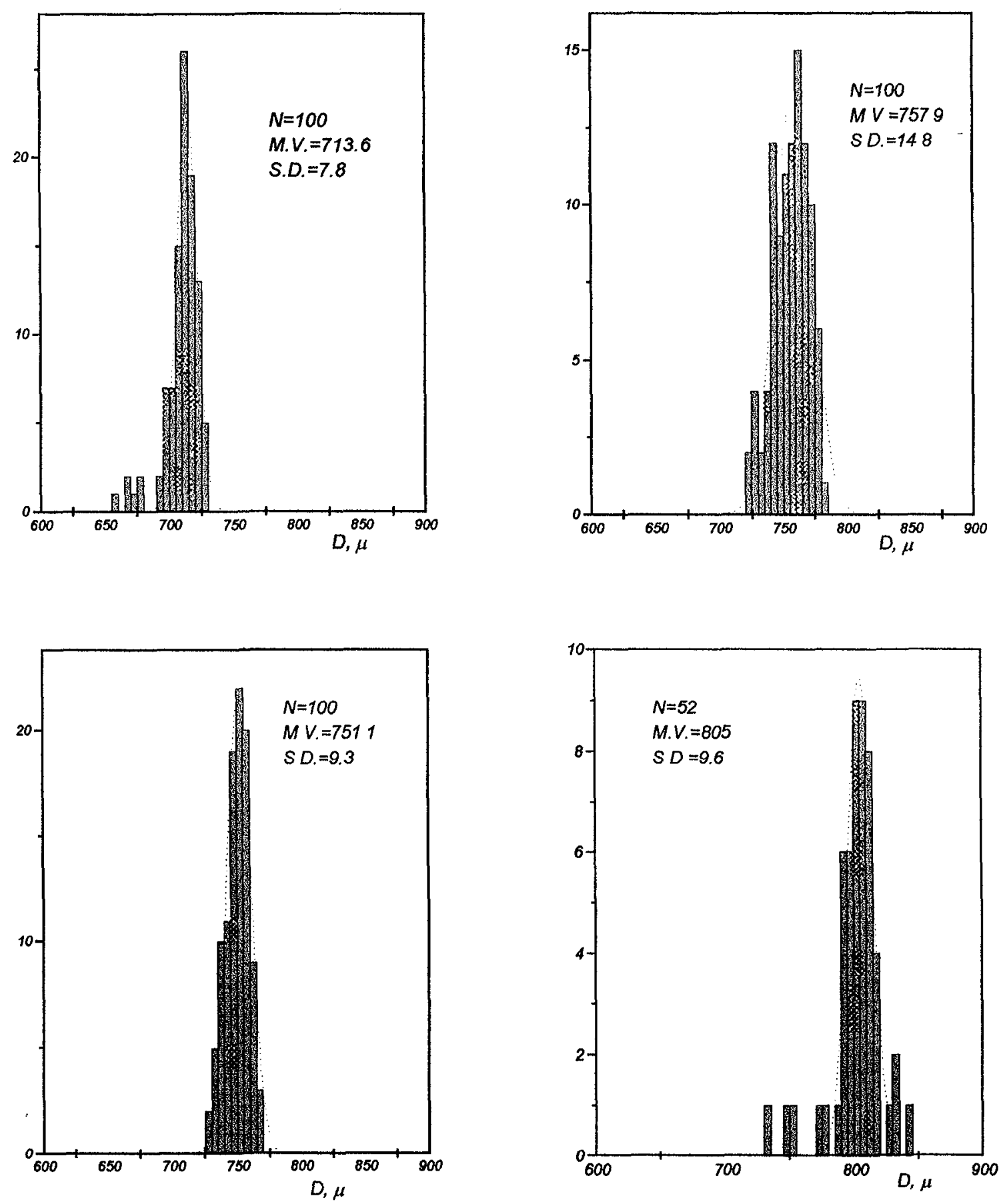

Fig. 2. Initial granules diameter distribution for granule's fraction used in experiments (D - diameter,

M.V. -- mean value, S.D. -- standard deviation, $\mathrm{N}$-- number of measured granules, dashed line - gaussian fit). 
For the same reason it was very interesting for us to look more detailed at granule's inner structure and its surface. We have taken pictures of initial granules under microscope. To examine granule's inner structure they were put into the liquid with high refraction index (glycerol). To take picture we used digital camera KODAK DC40 directly connected to the microscope and computer. Several typical photographs are presented on fig. 3-5.
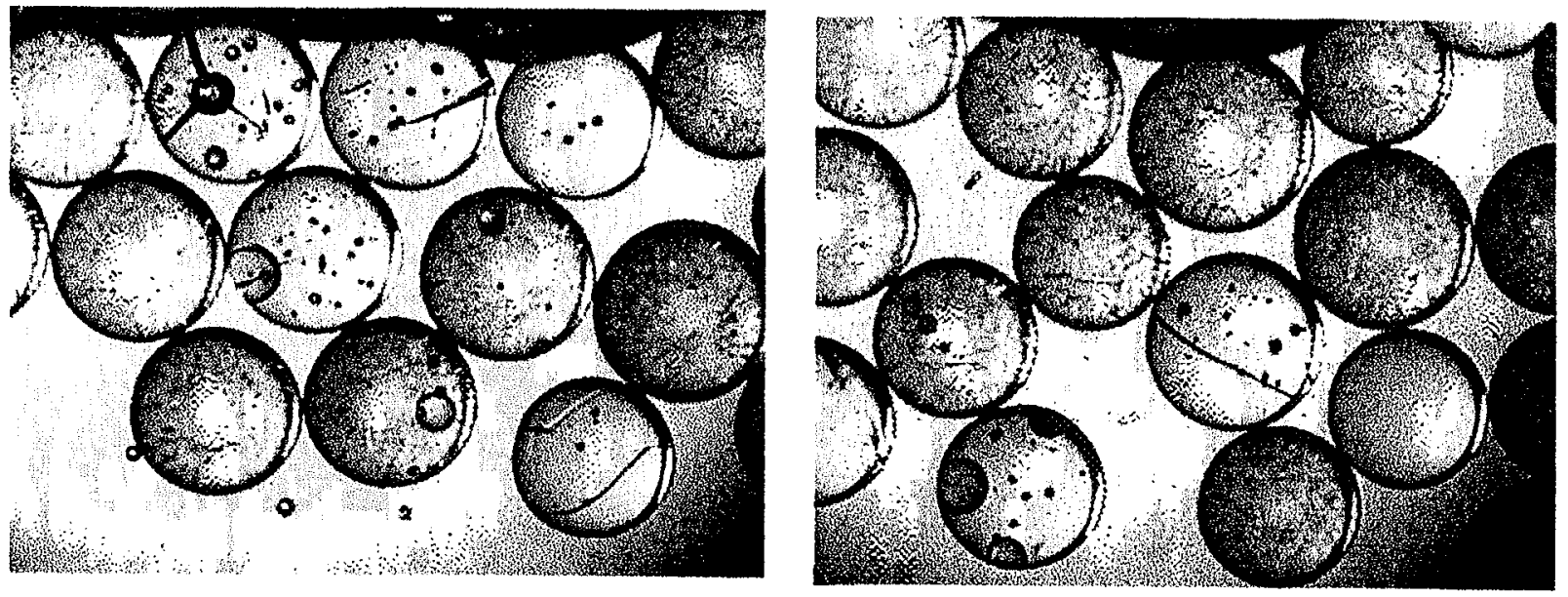

Fig. 3. View of the initial granules batch. Mean diameter - $700 \mu$.

One can see on fig. 3 two kinds of granules. Some of them (see fig. 4) have many shallow cracks on their surface. The surface of such granule looks like an orange skin. Depths of cracks are $10-30$ microns. Another granules (fig. 5) have a few deep cracks. Some cracks exceed the center of granule.
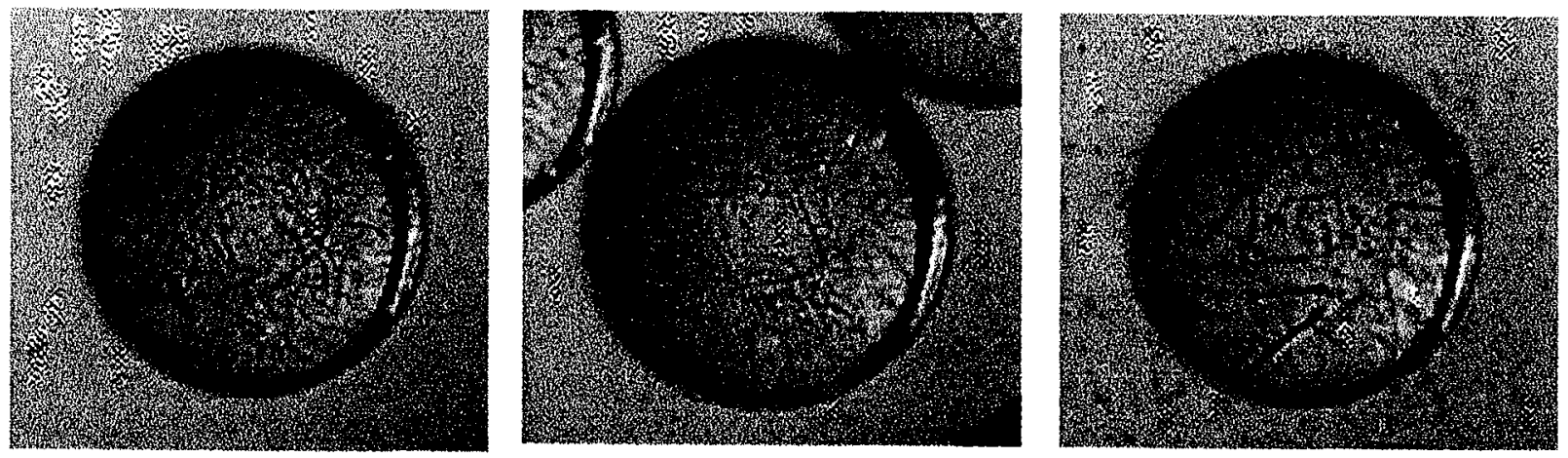

Fig. 4. Initial granules with shallow cracks on their surface 

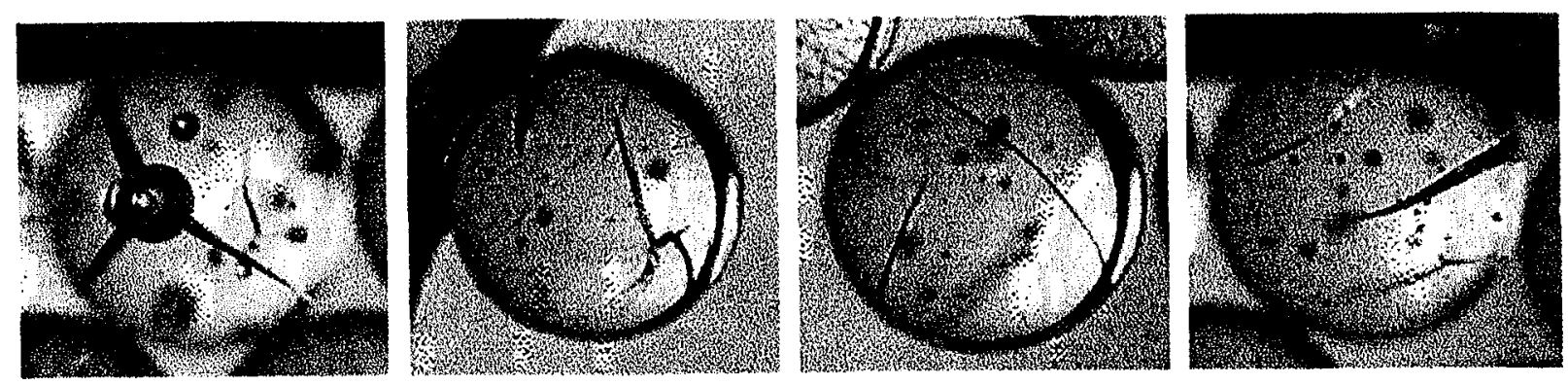

Fig. 5. Initial granules with deep cracks. One can clearly see also small cavities inside granules.

In both cases there are small spherical cavities (vacuoles) inside practically each granule. Their diameters can be from several microns (apparently there are smaller vacuoles, but we can not see such objects because of limited microscope optical resolution) up to more than 100 microns.

There is another interesting fact. Fresh initial granules, just after fabrication, look in the mass noticeably better - almost without cracks. However in process of time they degrade quite fast (in a few days). On the other hand we did not observed noticeable difference using fresh and old initial granules for shells formation experiments. Results were approximately the same.

\section{Activity in the Ballistic Furnace design.}

To convert pressure and temperature to digital form we had used amplitude-to-

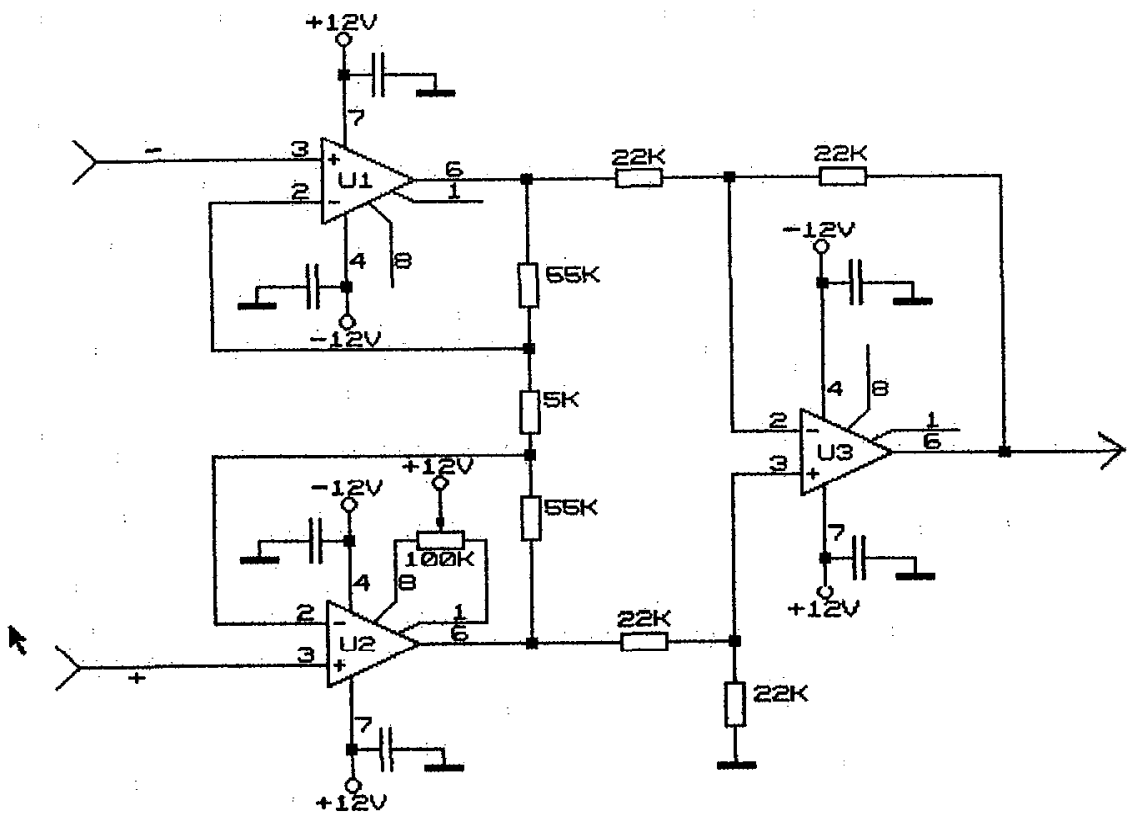

Fig.6 Amplifier.

digital-converter ADC-701 in CAMAC standard. When it failed we were needed to 
purchase new ADC and made new precision amplifier to match signal levels. We have chosen classical scheme for it. Figure 6 shows this device with very low own noises and amplification coefficient 23 .

\section{Shells fabrication experiments.}

In the last set of experiments we were trying to produce shells from $0.7-0.8-\mathrm{mm}$ initial granules using granules' fractions $-0.714,0.723,0751,0.758$ and $0.783 \mathrm{~mm}$. Size distribution for some granules' fractions are presented on Fig. 2.

Operating pressure was maintained in the range 0.05-0.15 atm and temperature varied from $760^{\circ} \mathrm{C}$ up to $870^{\circ} \mathrm{C}$. We could not produce any good shells from $0.7-0.8 \mathrm{~mm}$ initial granules at temperatures below $750^{\circ} \mathrm{C}$. We didn't vary temperature profile in the hot zone during our experiments and maintained it near uniform. The furnace atmosphere consisted of one volume part of $\mathrm{N}_{2}$ for thrce parts of $\mathrm{Hc}$. As for molccular mass of granules' material and its other properties, they were the same as we pointed in the previous report.

Initial velocity of the injected granule was in the range $5.8-7.0 \mathrm{~m} / \mathrm{sec}$. We had

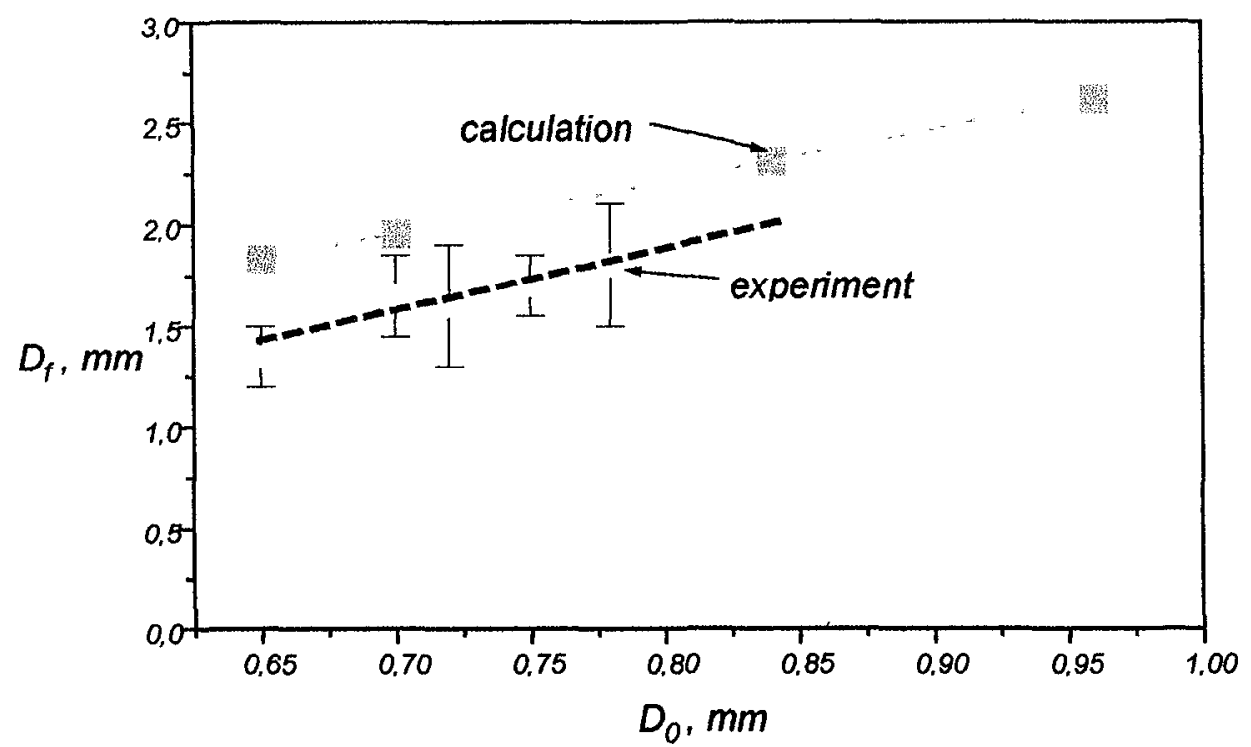

Fig. 7. Dependencies of final shells' diameter on initial granules diameter.

not observed good shells formation at velocities out of this range.

Results of the last experiments confirm our preliminary data reported early (see previous quarter report). Diameters of shells produced from one fraction are in the narrow size range and weakly depend on operational conditions (if shells were formed under this condition at all).

Our last results, previous data and results of modeling calculations are presented on fig. 7. Qualitative coincidence between experiment and calculation is seen at this picture. 
It is possible to make least square fit (dashed line) with more complete experimental data. Modeling calculations and experimental data show the same tendency.

\section{Discussion}

It seems possible to produce $2 \mathrm{~mm}$ shells from $0.85-0.95 \mathrm{~mm}$ initial granules based on data presented on fig. 7. However our attempts to produce good shells from granules with diameter more than $0.8 \mathrm{~mm}$ were unsuccessful. The main reason of this fact is small height of the hot zone. Apparently $1-\mathrm{m}$ hot zone is not enough for larger shells formation.

To solve this problem we are going to upgrade ballistic furnace increasing the Fig. 8.

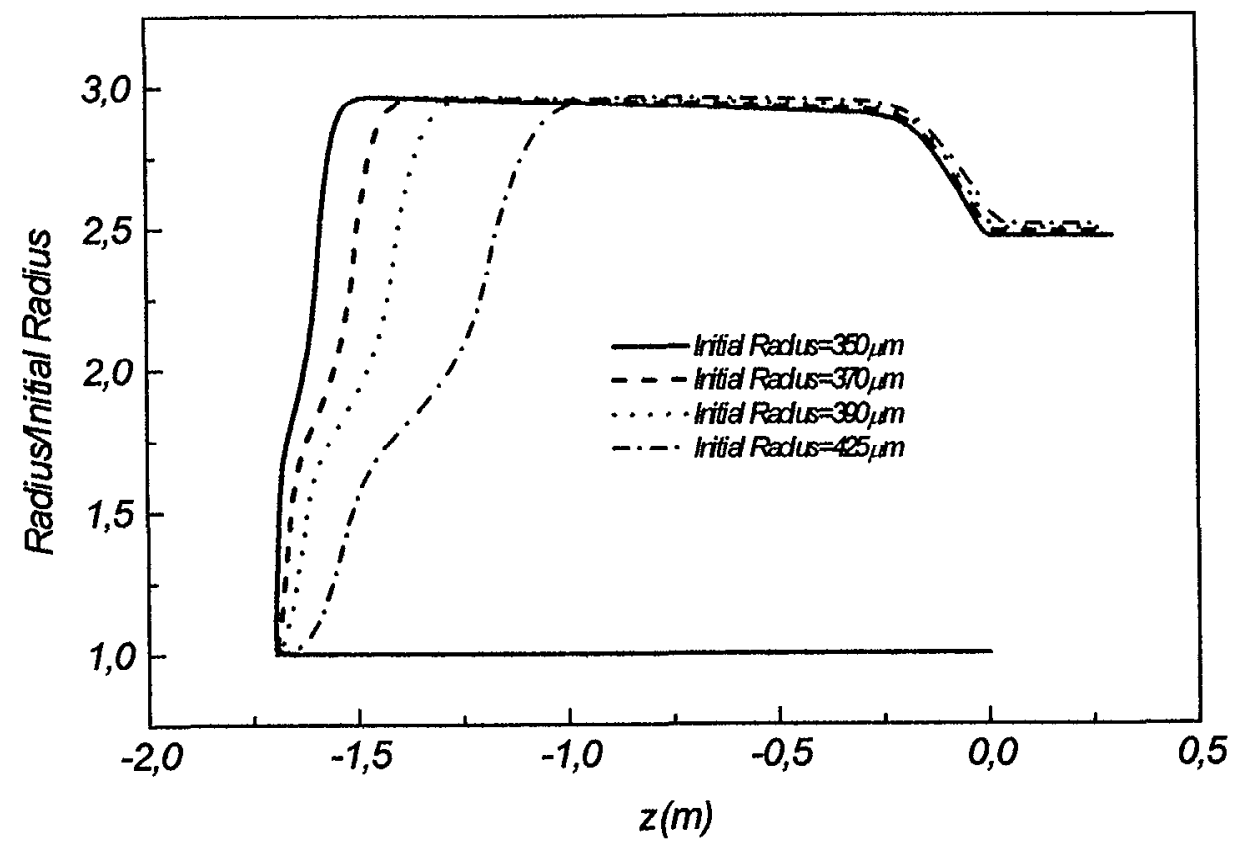

Shell and/or granule radius against its position in upgraded ballistic furnace. Modeling calculation. Position pointed with respect to injection point. Temperature profile is near to real one. $\mathrm{T}_{\max }=850^{\circ} \mathrm{C}$. Injection velocity is optimal for each curve.

not zone and the cooling zone length. Now we have almost ready additional hot zone unit and new cooling zone. Modeling calculation of shells formation process were made for $1.5 \mathrm{~m}$ hot zone. Results of the calculations indirectly confirm possibility of larger shells producing in 1.5 hot zone. One version of such results is presented on fig. 8.

It is interesting that final shell radius/initial granule radius ratio is practically independent on initial radius and different parameters. Experimental data show similar tendency. According to fig. 8 we could be produce $2 \mathrm{~mm}$ shells from $0.8 \mathrm{~mm}$ granules. This estimation is less than estimation based on experimental data scaling, but both show possibilities of $2 \mathrm{~mm}$ shells producing with upgraded ballistic furnace.

We are recognizing another possible ways for shell size increasing. One of the ways is special prepared initial granules using. For example it may be granules with large cavity 
in the center (empty or filled with water). However it is hard for us to develop this technology and to check its validity in a reasonable time.

Another approach is to select carefully the best operational conditions for shells producing with modern installation. We did not generally varied hot zone temperature profile in our experiments. On the other hand there are some experimental data obtained with the ballistic furnace and gravity one pointed at a pronounced effect of the temperature profile on shells formation process. We can not answer will this approach be valid or not basing on our modern knowledge. Anyway we are planing to investigate the temperature profile influence on shells formation process with upgraded ballistic furnace.

\section{Conclusion}

In conclusion we want to summarize the results of our activity at $12^{\text {th }}$ quarter.

1. Technical items:

- improved technique for granules separation had been developed and used in the last experiments.

- precision electronic equipment for temperature monitoring had been made, adjusted and put into operation.

- half-length hot zone had been manufactured and assembled.

- new cooling zone with water cooling had been manufactured and tested.

2. Experimental results:

- large set of experiments with 0.71-0.8 mm narrow size distribution initial granules was carried out and stable shells fabrication regimes for some granules fractions were found.

- it was confirmed that final sizes of formed shells weakly depends on operational conditions.

- complete set of experimental results with allowance for new data had shown qualitatively coincidence with model calculations.

- scaling for size of shells produced with $1.5 \mathrm{~m}$ hot zone had been made based on complete experimental data and extended modeling calculations. It shows opportunity of $2 \mathrm{~mm}$ shells production with upgraded ballistic furnace.

In the near future we are going to make ballistic furnace upgrade. We have stopped current experiments with the ballistic furnace now and started to prepare installation for upgrading. As things go we hope to continue experiments with the new ballistic furnace in early autumn.

We want to thank V.M.Dorogotovtsev's group for supplying the initial granules, S.A. Startsev for his computer code \& A.I.Gromov for characterization support. 


\section{EXPERIMENTS AND MODELLING OF THE POLYMER-SHELL FORMATION AT NUMEROUS NUCLEATION.}

\subsection{Introduction.}

Earlier we developed a mathematical model of the hollow microsphere formation from solid granules, which contain easy-boiling agents $[1,2,3]$. In that case we supposed that a single supercritical nucleus of the gas phase is formed in the center of the granule. This nucleus grows due to the coming gas-foamer and/or easy-boiling solvent. Experimental results correlate well with results computed in accordance with mathematical model in experiments on fabrication of small $(200-300 \mu \mathrm{m})$ polymer hollow microspheres and in experiments on shell formation from the gel of alkali silicates, containing water residuals and other foamers. The number of particles obtained in the form of foam particles was not high.

The task of the formation of large shells as laser targets made us to work with large polymer granules. But when the size of the initial polymer granules increased, the more foam pieces appeared and this process began to dominate. The shells were formed rarely. The optimized shcll fabrication regime (the furnace temperature increase, the gas pressure decrease in the furnace atmosphere and so on) leads to the sharp increase in the shell yield. Thus, a demand arose to develop the new mathematical model, which takes into account the multiple nuclei formation, foam fragment formation and foam destruction with the final polymer shell formation.

There are only several publications in which the mathematical model of the polymer foam dynamics is presented [4-7] for the infinite space under isothermal conditions, in the low-temperature domain (in the case of polymer high viscosity or viscous-elastic deformation) without taking into account the foam degradation with time. In industry the stability of the obtained foams is important [6,7], but we need to investigate the process of the quick foam degradation (in $0.1 \mathrm{sec}$.).

We tried to calculate the dynamics of the foam formation in relatively small volumes, including the degradation (destruction) of the foam inside the already formed liquid shell. Physical designations, conditions and applied mathematical methods are the same as in our previous works $[1,2]$ so, we do not represent them in detail.

\subsection{Experiment.}

To analyze the process of the formation and destruction of polymer foams in microspheres, we used our vertical furnaces [2,8]. But to obtain the information on the granule structure in the process of heating, we used short hot zones $0.3 \mathrm{~m}, 0.5 \mathrm{~m}$, and $0.7 \mathrm{~m}$. Thus we tried to diminish the intermediate 
stages of the microsphere formation. We also decreased the gas heat-transfer coefficient of the furnace atmosphere, varying the argon-hclium mixture of atmosphere composition from the traditional one-to-three ratio to the three-toone ratio.

Spherical polystyrene granules with molecular mass $\mathrm{M}=0.8 \cdot 10^{5}$ and polydispersity of 3,8 are used as initial granules. Granule diameter is about 560 $\mu \mathrm{m}$. They are saturated with ethyl acetate up to $6 \%$ by height. Particles with the diameter close to the average diameter in the particle distribution are selected among the foamed microspheres. These particles were glued to the stickholders, then discs were cut from them. The discs were thin (the thickness about $0.2 \mathrm{~mm}$ ) equatorial zones [9]. The structure of the polymer in these discs was investigated under optical microscope both in reflected and in incident beams. The average size (average diameter) of the foam cells was measured, beginning from the center up to the exterior bound. For the most part the foam cells were of the polyhedral structure. Two mutually perpendicular diameters were measured. In doing so we tried to choose one of the diameter directions coinciding with the direction of size gradient (i. e. the direction in which the foam is mostly non-uniform).

We obtained a great variety of structures, but we should note the following basic results:

1. All specimens-microspheres can be divided into four groups: the shells (low yield), the nearly solid particles (small part), the capsules with foam inside, foam particles without thick exterior layer (without a capsule). We paid a special attention to capsules with the foam inside.

2. There was no non-foamed domain in the center of foamed capsules (for the foam coefficient $\mathrm{K}=\mathrm{R}_{\mathrm{o}}{ }^{3} / \mathrm{R}_{\mathrm{s}}{ }^{3}$ which is no more than 6).

3. The yield of capsules with the foam inside grew higher at the decreased heat transfer or in the short hot zone $0.3 \mathrm{~m}$. Quite unexpectedly the size of the foam cells was nearly the same along the whole capsule diameter, but the heating regime effected the cell size, changing it from 15 to $60 \mu \mathrm{m}$.

4. At the intensive heating (high temperature and a high amount of helium) one can find more capsules with evident foam destruction in zones $0.5 \mathrm{~m}$ and more. Mainly, the foam layers, which adjoined the exterior shell, were destroyed, changing into threads, but the interior domain remained uniform with respect to the size of the foam cells. The foam particles with destroyed foam in the center (empty in the center) were found more rarely.

5. If the particles were fabricated at the intense heating in longer zones $0.7 \mathrm{~m}$ and $1 \mathrm{~m}$, then the majority of particles possessed the foam degradation and even monoshells were found. There were such capsules among those with foam degradation, in which there was no foam in the center and its remainders were pressed to the interior surface of the capsule.

These results and a lot of photographs of foam structure in capsules helped in calculations. 


\subsection{Mathematical model.}

In Fig. 1 physical processes are shown, which take place at the formation of a large polymer shell from the solid granule in the vertical furnace. This variant of the dynamics of the internal boiling in the microsphere differs from that described in our [1,2] by the presence of homogeneous domain in the center of the microsphere with the growing nuclei of the gas phase, which transforms into the foam domain. That is why the method to solve the heat transfer problem is changed and the dynamics of the viscous liquid differs significantly, as it contains the foam with definite viscosity (elasticity).

We analyze the problem with central symmetry. The granule is conditionally separated into two domains: the exterior spherical liquid layer, with no foam and the interior domain, which is the liquid with a great number of nuclei. The nuclci that evolve are situated at a definite average distance $\mathrm{L}_{\mathrm{f}}$ (this parameter we analyze in the end of the article, detail in $[9,12])$. The foam, which is formed in this domain, is broken in the center at the moment determined by the destruction criterion. Two domains are formed from it, the spherical layer of the foam remainders and the sphere, filled by gas.

To simplify the problem, we suppose that the foam domain is of the homogeneous uniform kind and the elastic gas and viscous-polymer foam properties are averaged over volume. The liquid moves due to the liquid surface tension and the pressure of gas extracted from the polymer liquid or from the liquid coming into the cavity (foam) from the furnace atmosphere.

As in the previous model [1-3], we solve the following system of equations: the equation of movement with the retardation in the furnace atmosphere; heat transfer with convective heat exchange at the microsphere boundary; diffusion of the gas-foamer and/or easy-boiling solvent and furnace atmosphere gases; and the equation of the viscous liquid dynamics. Only the last equation differs principally from that one of the previous model. In the case of heat conductivity equation and diffusion equation complications are not of the principal kind.

Our calculations of the nucleus formation intensity $\mathrm{J}(\mathrm{r}, \mathrm{t})$ is represented in Appendix 1 and [10] and it is similar to calculations in $[6,7,11]$. But contrary to $[6,11]$ we take into account the fact that the gas-foamer is non-ideal one, as well as the influence of solvent concentration $C(r, t)$ on the surface tension, the variation of the liquid potential energy at the introduction of the foamer and at the heating, and heterogeneous nucleus formation in the microcavities.

The initial distribution of the foamer $C(r, 0)=C_{o}\left(R_{S} / \pi r\right) \sin \left(\pi r / R_{S}\right)$ corresponds to the solvent distribution in the partly dried granule. External layer have the low solvent concentration $\mathrm{C}(\mathrm{r}, \mathrm{t})$ and have not embryos of gas bubbles Our designations, analogous are represented to [1].

In $[10,12]$ we showed that in the case of such foamer distribution the capsule of $\Delta R_{s}$ thickness is formed (with the foam inside). Also we showed in 
[12] that in the isothermal case at high temperature the average initial distance between cells is $L_{f}$, i.e. the foam size dispersion is small about $L_{f}$

$$
L_{f}=\sqrt[3]{\frac{1}{J \tau_{H D}}} \quad \text { at } \tau_{H D}=\frac{L_{f}}{2} \sqrt{\frac{\omega \eta}{\pi^{2} S P_{o} D}} \approx 10^{-3} \mathrm{sec} .
$$

In the non-isothermal case the first growing layer of bubbles significantly changes the geometry of the heat transfer problem and conditions of the foaming of the microsphere central domain after the bubbles' radii become 0.5 $\mathrm{L}_{\mathrm{f}}$, (see Fig. 1). In accordance with [12], let us write the condition $T_{f} \geq T_{c r}$ that is the temperature in the beginning of foaming is higher than the critical temperature of the gas-foamer. $T_{c r}=250^{\circ} \mathrm{C}$ for ethyl acetate and polystyrene with molecular mass about 105 . At this temperature the polymer viscosity $\eta$ decreases to $\eta=100$ Pa.s. It is easy to show that the microsphere heat content is high enough for $\Delta R_{s}=0.2 R_{s}$ and the microsphere can perform foaming without the complementary heating.

\subsection{Liquid dynamics equations and solutions.}

Features of the liquid dynamics in this model may be illustrated by the isothermal variant, which corresponds to the simultaneous foaming of the foam domain, which contains $\alpha_{x}$ - the volume fraction of polymer. In doing so the interior boundary of the non-foamed layer $r_{i}=r_{i}(t)$ moves according to the law $r_{i}=\sqrt[3]{\alpha_{x}} R_{s}\left(1+\frac{t}{\tau_{H D}}\right) \quad$ up to $r_{i}=r_{i j}\left(t_{x}\right)$

where $\mathrm{r}_{\text {if }}$ is approximately equal to $\quad r_{i f}=R_{S} \sqrt{\frac{\alpha_{x} \gamma_{S} \mu_{p} V_{M g} P_{n} T_{o}}{3 \mu_{g} V_{M p} P_{o} T_{n}}}$

here $\gamma_{S}$ is weight fraction of solvent in polymer, $\mu_{g}, \mu_{p}$ and $V_{M g}, V_{M p}$ are molar weight and volume solvent and polymer, $P_{n}, P_{o}$ and $T_{n}, T_{o}$ are normal and furnace pressure and temperature.

In doing so the initial exterior non-foamed liquid layer decreases, but the gas-foamer (easy-boiling solvent) still remains in it, as the time of foaming $t_{x}$ is less than the time of diffusion outflow $\tau_{D}$ from the spherical liquid layer of $\Delta R_{s}=\left(r_{0}-r_{i}\right)$ thickness. The time $\tau_{D}=\left(r_{O}-r_{i}\right)^{2} / D$ is approximately equal to $0.02 \mathrm{~s}$ at $\mathrm{D}=10^{-9} \mathrm{~m}^{2} / \mathrm{s}$.

Navier-Stokes equation and the equation of continuity for the spherically symmetrical case remain the same, but the boundary condition at the boundary between the liquid and the foam differs from the boundary condition at the liquid-gas boundary (point over $\mathrm{r}$ is derivative with respect to $\mathrm{t}$ )

$$
P_{i}-\frac{2 \sigma}{r_{i}}-3 \eta \frac{d r_{i}}{r_{i} d t}\left(\frac{\alpha_{x} R_{s}^{3}}{r_{i}^{3}}\right)=P-2 \eta \frac{\partial \dot{r}}{\partial r} \quad \text { at } r(t)=r_{i}
$$


by the third term in the left part of the equation, which corresponds to the elastic pressure (viscous tension) of the foam. Similarly we can calculate the volumeaverage foam viscosity.

To obtain the equation of dynamics in the isothermal case

$$
\begin{aligned}
& \frac{\varepsilon_{i}\left(1-\alpha_{x}\right)}{3}\left\{\frac{\ddot{y}}{y^{2}}+\frac{2 \dot{y}^{2}}{y^{3}}\left(1-\frac{2}{y}\right)\right\}+4 \frac{\eta}{P_{o}} \frac{\dot{y}}{y}\left(1-\frac{\alpha_{x}}{4 y^{3}}\right)+1+\varepsilon_{L} \frac{1}{y}=\frac{P_{i}}{P_{o}} \\
& \text { where } y=\frac{r_{i}}{R_{s}}, \varepsilon_{i}=\frac{\rho R^{2}}{P_{o}}, \varepsilon_{l}=\frac{4 \sigma}{P_{o} R_{S}} \text { at } y(x)=y\left(\pi^{2} D t / R_{S}^{2}\right) \text {, and point under }
\end{aligned}
$$

$\mathrm{y}$ main derivative with respect to $\mathrm{x}$ - dimensionless time,

we integrate the equation of Navier-Stokes over the volume from the interior $r_{i}$ (at $r_{i}(0)=\sqrt[3]{\alpha_{x}} R_{S}$ ) to the exterior $r_{o}\left(\right.$ at $\left.r_{o}(0)=R_{S}\right)$ boundary of liquid using the equation of continuity similarly to [1].

To calculate the internal pressure $P_{i}$ we solve the diffusion equation.

As a first approximation, we obtain the solution of the dynamics equation for the two time intervals. The first one, when the bubble develops without influence of its neighbors $r_{i}<<R_{S}$; the second one, when the foam is already formed, but its volume increases at the cost of the gas extracting from the liquid spherical layer, i.e. the shell, which contains foam, extends. If the foam consists of the open cells, then in accordance with [1] we can obtain the equation of the shell dynamics neglecting the inertial components by differentiation of the gas law using the Ficke law

$$
\varepsilon_{H}\left(\frac{\ddot{y}}{y^{2}}+\frac{2 \dot{y}^{2}}{y^{3}}\right)+\frac{\dot{y}}{y^{2}}+\frac{2 \varepsilon_{L} \dot{y}}{y^{3}}=\frac{3 S}{\omega\left(1-\alpha_{x}\right)} \exp \left(-\frac{36}{\pi^{2}} \frac{y^{4} x}{\left(1-\alpha_{x}\right)^{2}}\right)
$$

If we compare the movement of the shell without foam [1] with the movement of the shell with foam inside, we can see the retarded movement. At the initial stage $r_{i} \leq R_{S}$ the shell with the foam moves quicker $y_{f}(x)=f(x)$ than the shell without foam $y_{o}(x)$, but then it retards. Approximately, $y_{o}(x) \approx \sqrt{f(x)}$, but diffusion time decrease by factor approximately $\left(1-\alpha_{x}\right)^{-1}$, see Figure 2 .

Let us return to the moment of the start of the shell with foam. We supposed that foam cells are open, but it is not so in our case. Then the coefficient in the equation (1) changes from 3 to 6 . We did not properly investigate the behavior of the foam when it was pressed by gas coming from the liquid exterior layer. It is clear that external cells begin to increase, pressing the interior domain, breaking the tangential foam partitions and making thinner the radial partitions, which turn into threads. The pores in the next rows will be filled in time $\tau_{d} \tau_{d} \approx^{d_{c}} \delta / \Gamma D P_{n}$, where $d_{c}$ is the cell diameter, $\delta$ is the thickness of the tangential film (the cell wall). By the order of value, $\tau_{d}$ is close to $\tau_{d}$ for the liquid layer. 
Starting to develop this mathematical model we supposed that the complementary force which expands the foam over radius at the stage of the shell expansion generates the necessary effect on the destruction of the foam partitions in the microsphere center. But experiments do not show such phenomenon (it may occur only from time to time).

The condition of the foam cell film to break is $P_{i} \geq[\sigma]_{l l} \delta / d_{c}$ (A. A. Berlin's condition of destruction). Here $[\sigma]_{e l}$ is the limit strength at the momentary expansion.

The break of the foam with the open pores in the center (at the initial asymmetry) leads to the quick (in a time $\tau_{c}$ ) foam absorption into liquid polymer surface layer $\tau_{c} \approx 3 \eta \delta / 2 \sigma$. The central destruction of the foam with closed cells can produce the complete destruction of the foam. It leads to the monoshell formation in the following cases: the viscosity of the polymer $\eta$ is very small (the presence of the solvent or high temperature) or foam films are very thin (for polystyrene $\delta<0,5 \mu \mathrm{m}$ ).

The foam destruction with foam fragments drawn into shell liquid completes the shell formation. The following compression due to the surface tension, shell's cooling and contraction are completely described by the previous model $[1,2,3]$.

\subsection{Conclusion.}

The following basic principles of the model of large polymer shell formation at the multiple nucleus formation are developed:

1. The intensity of the nucleus formation $J$ is calculated and the characteristic distance between supercritical nuclei $L_{f}$ is obtained (see $\Lambda$ ppendix 1).

2. It is shown, that at high polymer viscosity the nuclei development is so slow that we can consider these nuclei not to develop until the temperature reaches $250^{\circ} \mathrm{C}$. But at this temperature there is enough heat energy in the granule for the foaming of the whole particle.

3. We introduced the criterion of the foam breaking, which is close to the criterion which we used earlier [1] from the physical point of view.

4. We obtained the equation of the polymer granule dynamics, which contains polymer foam inside.

5. The first calculations and estimations were applied to our experiments and recommendations were worked out: slow heating at the initial stage of the hollow microsphere formation, higher saturation of granules by the solvent and the introduction of 1-2 weight percent of water. 


\subsection{References.}

1. Yu. A. Merkul'ev. Fundamentals of Hollow Microshperes - Microballoons Technology. In "Laser Termonuclear Targets and Superdurable Micrjballoons" ed. A. I. Isakov, Nova Science Publishers, NY, 1996, pp. 141-230.

2. Yu. A. Merkuliev, A. A. Akunets, V. S. Bushuev, V. M. Dorogotovtsev, A. I. Gromov, A. I. Isakov, A. I. Nikitenko, S. S. Startsev, S. M. Tolokonnikov and R. C. Cook. Study of Production and Quality of Large (2mm) Polystyrene Hollow Microspheres. In "Hollow and Solid Spheres and Microspheres - Science and Technology Associated with Their Fabrication and Application" ed. D. L. Wilcox, Proceedings of Material Research Society V. 372, Pittsburgh, PA, pp. 119-124.

3. Yu. A. Merkuliev, $\Lambda$. S. Startsev and R. C. Cook. Simulation of High Temperature Formation of Large $(2 \mathrm{~mm})$ Polystyrene Shells from Solid Granules". In Proceed. $11^{\text {th }}$ Target Fabrication Specialists' Meeting, Orcas Island, 1996, pp. 269-281.

4. A. N. Gent and D. A. Tompkins. Nucleation and Growth of Gas Bubbles in Elastomers. J. Appl. Phys. V. 40, No 6, 1969, pp. 2520-2525.

5. S. Y. Hobbs. Bubble Growth in Thermoplastic Structural Foams. Polymer Engineering and Science, 1976, V. 16, No 4, pp. 270-275.

6. M. Amon and C. D. Denson. A Study of Foam Growth: Analysis of the Growth of Closely Spaced Spherical Bubbles. Polymer Engineering and Science, 1984, V. 24, No 13, pp. 1026-1034.

7. M. Amon and C. D. Denson. A Study of the Dynamics of foam Growth: Simplified Analysis and Experimental Results for Bulk Density in Structural Foam Molding. Polymer Engineering and Science, 1986, V. 26, No 3, pp. 255-267.

8. A. A. Akunets, V. M. Dorogotovtsev, Yu. A. Merkuliev, S. A. Startsev, R. Cook. Production of Hollow Microspheres from Solid Plastic Granules. Fusion Technology, 1995, V. 28, No 5, pp. 1781-1786.

9. N. G. Borisenko, $\Lambda$. A. Gromov, Yu. A. Merkul'ev, and A. V. Mitrofanov. Low-Density Laser Targets Fabrication. (It was submitted in Journal of Moscow Physical Society).

10. Yu. A. Merkul'ev and A. P. Turivnoy. Nucleation in Two Components Liquids. (It was submitted in Journal of Moscow Physical Society).

11. J. S. Colton and N. P. Suh. The Nucleation of Microcellular Thermoplasic Foam with Additives: Part1: Theoretical Considerations. Polymer Engineering and Science, 1987, V. 27, No 7, pp. 485-492.

12. Yu. A. Merkul'ev and A. P. Turivnoy. Phase Transformations in Polymers with Blowing Agents. (It was submitted in Journal of Moscow Physical Society).

13. А. А. Берлин, Ф. А. Шутов. Химия и технология газонаполненных высокополимеров. «Наука», Москва, 1980, 504 стр.

14. D. W. Van Krevelen. "Properties of Polymers", Elsevier, New York, 1976. 
Appendix I

\section{3a. PHASE TRANSITION DYNAMICS IN TWO-COMPONENT LIQUIDS.}

\section{3a.1. Introduction.}

To produce foam plastics in industry, the method of heating the large (6$8 \mathrm{~mm}$ ) polystyrene granules is applied. Granules contain low-temperature boiling admixtures, overheated by the water vapor ( $\left.T \cong 110-130^{\circ} \mathrm{C}\right)$ [1]. We use $[2,3]$ the method of granule heating in gases for the fabrication of hollow microspheres. The heat conductivity of chosen gases is high. We developed $[3,4]$ the mathematical model of polymer shell formation, in which a single bubble appears in the center of the sphere. But in large granules a lot of bubbles are born $[5,6]$, the foam is formed and only after that the polymer shell appears. To improve our mathematical model, we are to calculate the vclocity of the supercritical bubble generation and their influence on each other. To our regret, we can name only 3-4 publications [7-9], where the intensity of the nucleus formation is calculated in polymers, which contain a small amount of foamersadmixtures $(\leq 6 \%)$. In those works the gas is considered to be perfect, the polymer is of elastic kind and the medium "depletion", i. e. the decrease of the gas-foamer concentration in the process of the bubble development, is neglected.

Our technology of the polymer shell formation from the solid granules [2$6]$ is based on the particle heating to high temperatures, close to the temperature of the immediate destruction of polymer $[10,11]$. Therefore in calculations it is necessary to take into account the appearance of gas-like products of the polymer destruction. Thus the calculation of the nuclei formation becomes more complicated.

\section{3a.2. General statements.}

We describe the appearance of the growing bubble in the two-component liquid in the same way as in the one-component media, as a fluctuation event (for homogeneous nucleation [12])

$$
J_{\text {hom }}=N \beta \exp (-W / k T) \quad \text { at } G=(W / k T)
$$

Usually, $\mathrm{W}$ is the minimal cnergy of the new phase formation, in the onecomponent phase it is equal to $W_{\min }=W=16 \pi \sigma^{3} / 3\left(P_{V}-P_{L}\right)^{2} ; \mathrm{N}$ is the number of volatile molecules in the volume unit; $\beta$ is a frequency factor, which corresponds to the frequency of molecule collisions in the one-component media. $\left(\beta \cong 10^{12} \mathrm{~s}^{-1}\right)$, but if we calculate $\beta$ in weak solutions, it is necessary to take into account the diffusion delivery of gas $D(T)$ and the medium viscosity $\eta$ at the bubble growth; $\mathrm{k}=1.38 .10^{-23} \mathrm{~J} / \mathrm{grad}(\mathrm{J} / \mathrm{K})$ is the Boltzmann constant; $\mathrm{T}$ is 
the absolute temperature; $\mathrm{P}_{\mathrm{V}}$ and $\mathrm{P}_{\mathrm{L}}$ are the gas pressure and the pressure in liquid (an external pressure).

When substituting the value of $\mathrm{N}$ into (1), one should take into account that the total amount of the volatile molecules is distributed between homogeneous and heterogeneous nuclei:

$$
N=N_{\text {hom }}=N_{S}-N_{\text {heter }}
$$

here $N_{S}$ is a total number of volatile molecules on a volume unit;

$\mathrm{Nheter}$ is a number of volatile molecules in heterogeneous center of boiling on a volume unit.

$$
\text { Also } \gamma_{\text {hom }}=\gamma=\gamma_{S}-\gamma_{\text {heter }} \text {, }
$$

here $\gamma_{S}, \gamma$ and $\gamma_{\text {heler }}$ are full, homogeneous and heterogeneous weight fraction solvent in polymer.

To calculate $\beta$, we used the equation, which takes into account the diffusion of volatile molecules

$$
\beta=\beta_{1}\left[D(T) / 4 \pi r_{c}^{2}\right] \exp \left(-\beta_{2} / k T\right)
$$

here $D(T)$ is the diffusion coefficient of volatile molecules in polymer; $r_{c}$ is the radius of the critical bubble $r_{c}=2 \sigma /\left(P_{V}-P_{L}\right) ; \beta_{1}$ and $\beta_{2}$ are constants, which are chosen in accordance with experimental data.

The energy of the nuclei formation $W=W_{\min }-\Delta W_{1}-\Delta W_{S}$ is calculated taking into account the free volume of polymer $\Delta W_{1}$ and the variation of the chemical potential at the transition solvent from polymer solution in the gas or liquid solvent inside the bubble $\Delta W_{S} \quad[13,14]$.

$\Delta \mathrm{W}_{\mathrm{S}}$ is the variation of free energy at the cost of the chemical potential $\mu$ variation

$$
\begin{aligned}
& \mu_{g}-\mu_{S}=k T\left[\ln \gamma_{V}+\left(1-\gamma_{V}\right)+\chi\left(1-\gamma_{V}\right)^{2}\right] \\
& \Delta W_{S}=n k T\left[\ln \gamma_{V}+\left(1-\gamma_{V}\right)+\chi\left(1-\gamma_{V}\right)^{2}\right]
\end{aligned}
$$

here $\mu_{\mathrm{g}}, \mu_{\mathrm{S}}$ are chemical potentials of the gas-solvent and polymer-solution correspondingly; $\gamma_{V}=\gamma \frac{\mu_{p} V_{M g}}{\mu_{g} V_{M p}}$ is the solvent volume fraction in polymer; $\mathrm{n}$ is the number of molecules in the bubble; $\chi$ is the parameter, characterizing molecular interaction in polymer.

Free energy at the solvent introduction (removal) is calculated by formula

$$
\Delta W_{t}=n k T \ln [S(t)]
$$

where $\mathrm{S}(\mathrm{t})$ characterize the degree of solvent oversaturation in polymer at foaming

$$
P_{g}(t) / P_{V}=1+\varepsilon \ln [S(t)]
$$

where $\varepsilon$ is the parameter obtained in experiment.

In accordance with [14], for polystyrene and toluene of $40-60 \%$ the parameter $\varepsilon$ varies from 0.402 to 0.521 and, extrapolated to $4 \%$ and $8 \%$, these 
numbers are 0.187 and 0.211 correspondingly. The oversaturation $S(t)$ at the time $t$ is calculated using the equation of the viscous liquid dynamics

$$
\rho_{L}\left[r \ddot{r}+\frac{3}{2} \dot{r}^{2}\right]=P_{g}-\frac{2 \sigma}{r}-4 \eta\left(\frac{\dot{r}}{r}\right)-P_{L}
$$

Experiment shows that $\dot{r}=$ const . We have [15] a formula for the calculation of $\dot{r}=U$

$$
\begin{aligned}
\dot{r}=U & =\sqrt{\omega D P_{L} / \pi S \eta} \\
\text { Then, } P_{g}\left(t_{c}\right) & =\frac{3}{2} \rho_{L} U^{2}+\frac{2 \sigma}{r_{c}}+4 \eta \frac{U}{r_{c}}+P_{n c} \quad \text { at } t=t_{c}
\end{aligned}
$$

here $P_{n c}$ is critical pressure in liquid.

Using twice the expression (5) for the critical bubble and for the arbitrary bubble, we can obtain the value of $\mathrm{S}(\mathrm{t})$ in the arbitrary time-point. Thus we take into account the decrease of the gas-foamer concentration, $i$. e. the decrease of the easy-boiling component in the polymer or the medium "depletion".

\section{3a.3. Free space in polymer and calculation results.}

To calculate $J(\gamma, T, t)$, we must know series of dependencies $D(T), \eta(T)$ and so on. Some constants we can get from calculation based on the theory of the polymer free volume [16-17]. According to Van-Krivelan work [18] the polystyrene free volume is $13 \%, V_{f}=0.13 V_{p}, \gamma_{F H}=0.13$. To check the calculated values we can use published values of these constants measured at lower temperatures.

According to [17],

$$
D(T)=D_{o}\left(1-\chi \gamma_{V}\right)\left(1-\gamma_{V}\right)^{2} \exp \left(-\frac{E_{D}}{R_{g} T}\right) \exp \left[\frac{\hat{V}_{1} \gamma+\xi \hat{V}_{2}(1-\gamma)}{V_{H F} \varepsilon_{f}}\right]
$$

here $\hat{V}_{1}$ and $\hat{V}_{2}$ are the pore volumes, which are necessary for the diffusion jump of solvent molecules and polymer unit; $\mathrm{V}_{\mathrm{HF}}$ is the volume of the average pore in the polymer free volume; $\varepsilon_{f}$ is the factor of the size of solvent molecule to coincide with free-volume pore size; $\xi$ is the ratio of critical molar volume of solvent molecules to the critical molar volume of the polymer unit, taking part in the "jump" (diffusion motion); $\chi$ is the parameter of the solvent and polymer interaction.

After $\mathrm{D}(\mathrm{T})$ calculation, using experimental data, we can estimate $\beta$ parameter by formula (2)

For the calculation of the value $\mathrm{W}_{\min }$ it is necessary to estimate the surface tension $\sigma(\gamma, T)$ of the polymer solution at the boundary with the solvent (liquid one at $\mathrm{T}<\mathrm{T}_{\mathrm{cr}}$ and gas at $\mathrm{T}>\mathrm{T}_{\mathrm{cr}}$ ).

It is especially important to know the constant $\sigma$ at the temperatures, which are lower than the critical temperature of the solvent. As it is shown 
below, the supercritical nucler appear in the polymer at the temperature lower than the critical temperature of the solvent, if the external pressure is not high $\mathrm{P}_{\mathrm{o}}=\mathrm{P}_{\mathrm{L}}<3$ atm.

According to [18], $\sigma\left(T^{\prime}\right)=[\mathrm{Pa} / V(T)]^{4}$ where $\mathrm{P}_{\mathrm{a}}$ is a parahor, $\mathrm{V}(\mathrm{T})$ is a molar volume of polymer with solvent.

To calculate $\mathrm{P}_{\mathrm{a}}$ we used the data for of polymer and solvent at low temperatures [18].

The parahor $\mathrm{P}_{\mathrm{a}}$ is practically independent of temperature and depends weakly on the solvent concentration (227.3 and 229.9 for $4 \%$ and $8 \%$ solvent in polystyrene correspondingly) [17].

If the temperature is close to critical temperature, then the surface tension of the solvent can be taken as Van der Vaals $\sigma_{s}=\sigma_{o S}\left(1-T / T_{c r}\right) \quad$ (11a)

These expressions were used for rough estimations. In the case of calculations in the domain of small critical radii, commensurable with molecular size, we used the Tolman correction [19] to the surface tension,

$$
\sigma(R) / \sigma=1 / 1+2 \delta / R
$$

where the correction $\delta$ for polystyrene is considered to be $\delta=0.4 r_{L}$, where $2 r_{L}$ is the size of polymer unit (for polystyrene $2 r_{L}=0.67 \mathrm{~nm}$ [18]).

The dependence of the polymer solution viscosity on temperature and on the solvent concentration is represented by formula, which we used before [26]:

$$
\eta=\eta_{o}(1-\gamma) \exp \left(-A / T^{6}\right)
$$

The gas-foamer pressure in bubble $P_{V}$ are calculated (we assume $P_{L} \ll<P_{V}$ ) taking into account the gas non ideality (Van der Vaals) by formula

$$
P_{V}=\frac{R_{g} T}{V^{*}\left(1-V_{c r} / 3 V^{*}\right)}-3 P_{c r}\left(\frac{V_{c r}}{V^{*}}\right)^{2} \text { here } V^{*}=V_{M p} \frac{\gamma_{F} \mu_{g}}{\gamma_{\text {hom }}^{\prime} \mu_{p}}
$$

where $R_{\mathrm{g}}$ is gas constant, $V_{c r}$ and $P_{c r}$ are critical volume and pressure of blowing agent.

In fig. 1 the dependence of the molar fraction of polymer free volume $\gamma_{F}$ $\gamma_{F}=\gamma_{F H} \varepsilon_{f}+\gamma_{e x t}$

$\gamma_{F}$ is presented for the polymer cavities which can accept the solvent molecule $\gamma_{f o}=\gamma_{F H} \varepsilon_{f}$ (we assumed $\varepsilon_{f}=0.3[1+\alpha(T-273)]$, here $\alpha$ is volume coefficient of thermal extension) and $\gamma_{c x i}$ is free volume fraction of extension by boiling agents pressure. We calculated this temperature dependence taking into account the solvent density change near the critical point and polymer extension, i. e. the increase of the free volume (polymer swelling) 


$$
\gamma_{F}(T)=\gamma_{f o}+0.7 \gamma 0.8 \frac{T+T_{c r}}{T_{c r}}
$$

To calculate $\gamma_{\text {hom }}$ we must find $\gamma_{\text {heter }}$

$$
\gamma_{\text {heter }}=\left(\gamma_{T}+0.3 \gamma\right) 0.8 \frac{T+T_{c r}}{T_{c r}}
$$

where $\gamma_{T}$ is the fraction of the free volume, formed at the fabrication of solid polymer granules (usually these are bubbles $0.1 \mu \mathrm{m}-2 \mu \mathrm{m}$ in diameter with $\gamma_{T}=0.03-0.05$ ). Here we consider $\gamma_{T}=0.03$.

We used the temperature dependency $\gamma_{\text {hom }}=\gamma-\gamma_{\text {heter }}$ in that view

$$
\gamma_{\text {hom }}^{\prime}(T)=\gamma_{\text {hom }} \frac{b\left(T-T_{g l}\right)}{T_{c r}} \quad \text { at } b=2 \text { for ethyl acetate, }
$$

where $T_{g l}$ glass transfer temperature of polymer with solvent. For polystyrene with $\gamma=\gamma_{S}=0.06$ ethyl acetate $T_{g l}=350^{\circ} \mathrm{K}$.

In Fig. 2 and 3 dependencies $\sigma(\mathrm{T})$ and $\mathrm{P}_{\mathrm{V}}(\mathrm{T})$ are shown. In Fig. 4 dependencies $\mathrm{G}(\mathrm{T})$ are represented. It is obvious, that the homogenous nucleus formation at chosen solvent concentrations $(\gamma<0.12)$ is practically negligible at temperatures lower than $423^{\circ} \mathrm{K}$ (the critical temperature of the solvent-ethyl acetate is equal $523^{\circ} \mathrm{K}$ ).

\section{3a.4. Free space in polymer and heterogeneous nucleus formation.}

We supposed that the considered polymer has no microinclusions and other centers besides microbubbles, which appear in the tale of lognormal distribution of voids (free space of polymer).

$$
f(R)=\frac{1}{\sqrt{2 \pi} R \sigma_{1}} \exp \left\{-\frac{\left[\ln \left(R / R_{a}\right)\right]^{2}}{2 \sigma_{1}^{2}}\right\}
$$

Here $R_{a}$ is the distribution-average pore radius (we suppose that it is equal to $\left.\mathrm{R}_{\mathrm{a}}=0.35 \mathrm{~nm}\right)$ and $\sigma_{1}$ is a dispersion $\left(\sigma_{1}=0.4\right)$.

In Fig. 6 the number of voids (bubbles) in the volume unit is shown, for the bubbles, which are larger in size than the critical nucleus for the given temperature. It is clear that when heated a part of small bubbles in polymer is subjected to collapse $\mathrm{P}_{\mathrm{g}}=\mathrm{P}_{\mathrm{V}}<\mathrm{P}_{\mathrm{L}}$. The time $\tau_{c}$ of the bubble collapse under isothermal conditions can be found from the equation

$$
r_{i}=\sqrt[3]{r_{o}^{3}-\frac{3 R_{g} T \Gamma_{i} D \sigma}{\mu P_{i}}\left\{t-\frac{4 \eta}{3 P_{i}}\left[1-\exp \left(-\frac{3 P_{n} t}{4 \eta}\right)\right]\right\}}
$$

We can say that at quick heating a part of larger initial bubbles' decrease in diameter, but they become supercritical at a definite temperature. 

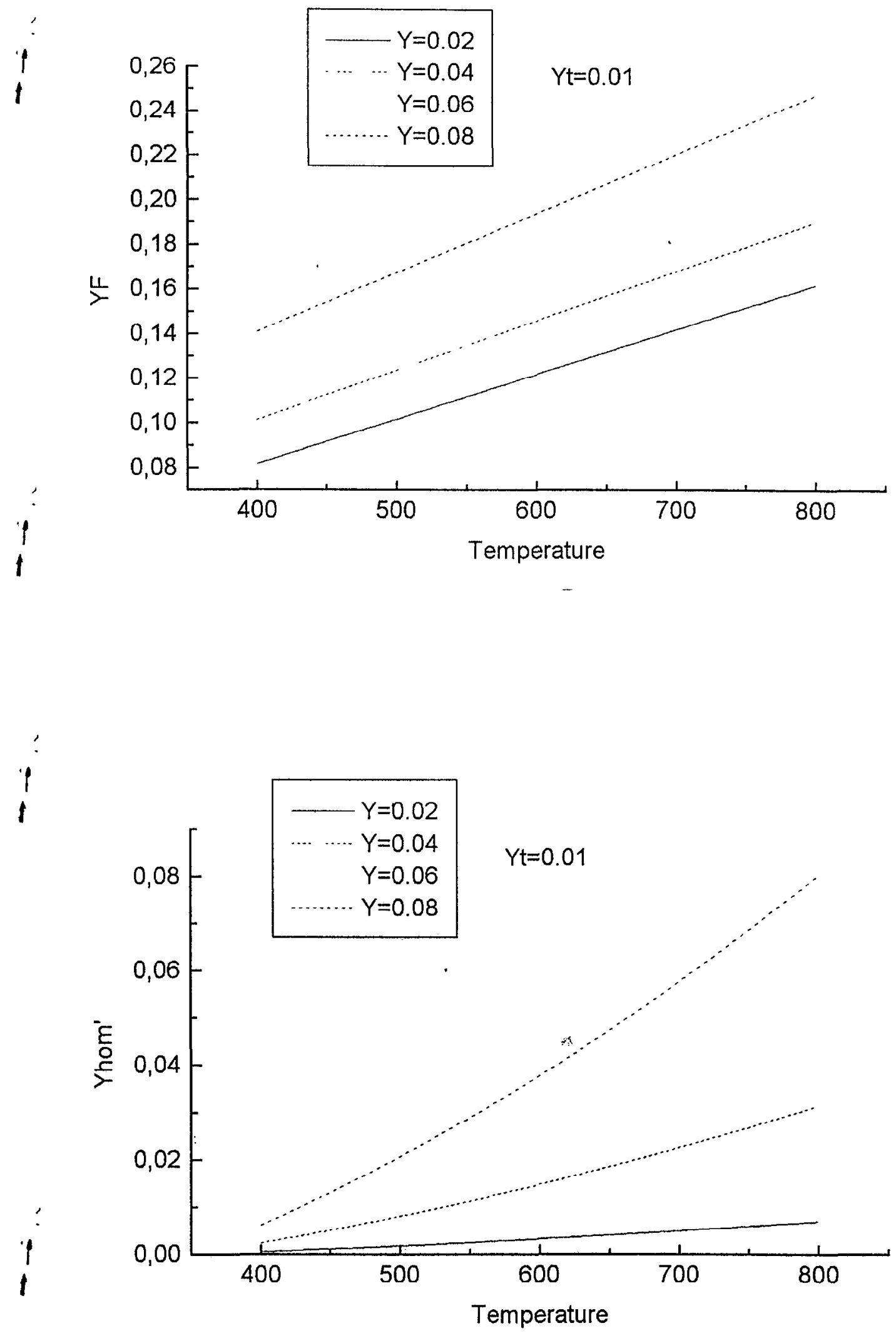

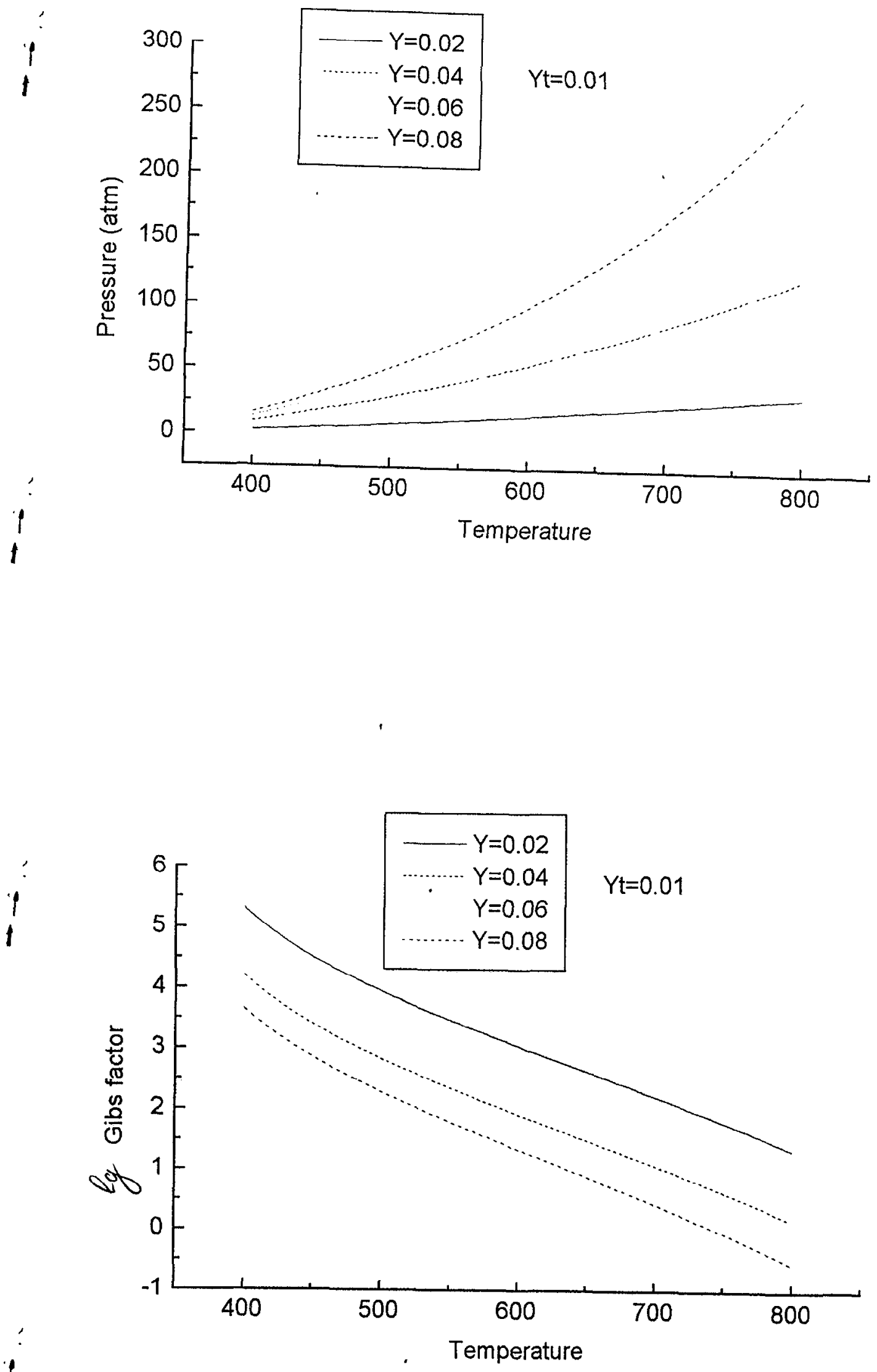
The quantity of such bubbles with $\mathrm{R}>\mathrm{r}_{\mathrm{cr}}$ may be estimated by integration of the function $f(R)$ (expression (17)) over the domain from $r_{c r}$ to $\infty$.

$$
N_{\text {heter }}=N_{o} \int_{c r}^{\infty} f(R) d R=\frac{N_{o}}{2} \operatorname{erfc}\left[\frac{\ln \left(r_{c r} / R_{a}\right)}{\sqrt{2} \sigma_{1}}\right]
$$

Here $\mathrm{N}_{\mathrm{O}}$ is obtained when the function is normalized. The total integral from $N_{o} R^{3} f(R)$ should result in a free volume (physical and technologic).

We can say that at quick heating a part of larger initial bubbles' decrease in diameter, but they become supercritical at a definite temperature.

In Fig. 5 the temperature dependencies of nucleus formation in polystyrene are shown for different concentrations of the solvent ethyl acetate.

In experiments $[1,11,12]$ on polystyrene granule foaming it is found that sometimes the polymer granules with the foam consisting of identical cells are formed. It is probably connected with the heterogeneous nucleus formation.

\section{3a.5. Conclusion.}

The application of the lognormal distribution to describe free space in polymers permits us to calculate the initial quantity of the supercritical nuclei at low temperatures and small concentrations of the foamer. At high temperatures and high quantities of the foamer it is necessary to take into account the homogeneous nucleus formation also.

\section{3a.6. References}

1.

2. А. А. Берлин, Ф. А. Шутов. Химия и технология газонаполненных высокополимеров. «Наука», Москва, 1980, 504 стр.

3. A. A. Akunets, V. M. Dorogotovtsev, Yu. A. Merkuliev, S. A. Startsev, R. Cook. Production of Hollow Microspheres from Solid Plastic Granules. Fusion Technology, 1995 , V. 28, No 5, pp. 1781-1786.

4. Yu. A. Merkul'ev. Fundamentals of Hollow Microshperes - Microballoons Technology. In "Laser Thermonuclear Targets and Superdurable Microballoons" ed. A. I. Isakov, Nova Science Publishers, NY, 1996, pp. 141-230.

5. Yu. A. Merkuliev, A. S. Startsev and R. C. Cook. Simulation of High Temperature Formation of Large $(2 \mathrm{~mm})$ Polystyrene Shells from Solid Granules". In Proceed. $11^{\text {th }}$ Target Fabrication Specialists' Meeting, Orcas Island, 1996, pp. 269-281.

6. N. G. Borisenko, A. A. Gromov, Yu. A. Merkul'ev, and A. V. Mitrofanov. Low-Density Laser Targets Fabrication Technology and Characterization Methods.

7. Yu. A. Merkul'ev and A. P. Turivnoy. Phase Transformations in Polymers with Blowing Agents.

8. S. Y. Hobbs. Bubble Growth in Thermoplastic Structural Foams. // Polymer Engineering and Science, 1976, V. 16, No 4, pp. 270-275.

9. A. N. Gent and D. A. Tompkins. Nucleation and Growth of Gas Bubbles in Elastomers. // J. Appl. Phys. V. 40, No 6, 1969, pp. 2520-2525. 
10. M. Amon and C. D. Denson. A Study of Foam Growth: Analysis of the Growth of Closely Spaced Spherical Bubbles. // Polymer Engineering and Science, 1984, V. 24, No 13, pp. 1026-1034.

11. Merkuliev Yu. A., Startsev S. A. Modeling the Effects of Polymer Degradation on the High Temperature Formation of Plastic Microshells. // (submitted to «Fusion Technology»).

12. Dorogotovtsev V. M., Akunets A. A., Merkuliev Yu. A., Turivnoy A. P., and Cook R. C. Thermal Decomposition for Polystyrene in the High Temperature Fabrication Technology of Hollow Microspheres at LPI. // Proceedings of Eleventh Target Fabrication Specialists' Meeting, September 8-12, 1996, Orcas Island, Washington, USA, pp. 211-220.

13. J. S. Colton and N. P. Suh. The Nucleation of Microcellular Thermoplasic Foam with Additives: Part1: Theoretical Considerations. // Polymer Engineering and Science, 1987, V. 27, No 7, pp. 485-492.

14. M. Amon and C. D. Denson. A Study of the Dynamics of foam Growth: Simplified Analysis and Experimental Results for Bulk Density in Structural Foam Molding. // Polymer Engineering and Science, 1986, V. 26, No 3, pp. 255-267.

15. J. H. Han and C. D. Han. Bubble Nucleation in Polymeric Liquids. II Theoretical Considerations. // J. of Polymer Science: Part B: Polymer Physics. 1990, Vol. 28, pp. 743 -761 .

16. Yu. A. Merkuliev, A. A. Akunets, V. S. Bushuev, V. M. Dorogotovtsev, A. I. Gromov, A. I. Isakov, A. I. Nikitenko, S. S. Startsev, S. M. Tolokonnikov and R. C. Cook. Study of Production and Quality of Large $(2 \mathrm{~mm})$ Polystyrene IIollow Microspheres. In "Hollow and Solid Spheres and Microspheres - Science and Technology Associated with Their Fabrication and Application" ed. D. L. Wilcox, Proceedings of Material Research Society V. 372, Pittsburgh, PA, 1995, pp. 119-124.

17. J. S. Vrentas and J. L. Duda. Diffusion in Polymer Solutions. // AIChE Journal, 1979, Vol. 25, No. 1, pp. $1-24$.

18. J. S. Vrentas and J. L. Duda. Diffusion in Polymer - Solvent Systems. I Reexamination of the Free - Volume Theory. // Journal of Polymer Science: Polymer Physics Edition, 1977, Vol. 15 , pp. $403-443$.

19. D. W. Van Krevelen. "Properties of Polymers", Elsevier, New York, 1976.

20. R. C. Tolman. J. Chem. Phys., 1949, Vol. 17, pp. 333 - 339. 


\title{
4. Processes of large polystyrene shells formation in the drop furnace. Results and discussion.
}

\author{
A. A. Akunets, V. M. Dorogotovtsev, A. P. Turivnoy.
}

\subsection{Introduction.}

Within the concluding quarter of the LLNL contract the efforts of the group "Microballoon fabrication technology" were divided between the three directions:

1. Making initial polystyrene granules by the suspension polymerization.

2. Special preparation and planned delivery of the initial polystyrene granules for the experiments on the ballistic furnace.

3. Studying the drop tower operation capabilities in order to work out requirements for the thermal maps inside the furnace to achieve the large polystyrene shells' formation.

Research of the formation processes for large (from $1.8 \mathrm{~mm}$ up to 3.0 $\mathrm{mm}$ ) microspheres by a method of foaming has shown, that temperature of a hot zone and gradients of temperature on the entrance and exit of a hot zone strongly influences the yield and surface quality of shells.

\subsection{Experiments.}

\subsubsection{Preparing of the initial granules.}

According to the preliminary theoretical estimations the experiments on the ballistic furnace require the initial polystyrene granules with a relatively narrow diameter divergence $(5-7 \%)$. The standard fractionating methods does not allow the needed accuracy. So we had to introduce the additional stage in the selection procedure - the sieving of the fractionated granules through the calibrated slot. The optical slit was used that was adjusted with the help of optical microscopc. This allowed us to achieve the necessary accuracy in the size equality of the remaining fraction. These distribution plots have been presented in the report of the "Ballistic furnace" group.

Unexpectedly because of intensive mechanical disturbance the initial granules became highly electrified. To solve the problem we were to do a number of tests so as to choose the optimum antistatic treatment. A solution of $7-10 \%$ of commercial antistatic in ethyl alcohol was found to be the best. 
The ballistic furnace studies needed to introduce clarity about the mass content of the foaming agent and the quantity of volatile residuals from polymerization stage.

To check the percentage of the light residuals a certain mass of initial granules was taken. It was placed for three hours inside the forvacuum chamber of $110 \pm 10 \mathrm{C}$ pumped to the pressure of $10^{-3} \mathrm{~mm} \mathrm{Hg}$. The mass difference was shown to be up to $4 \%$.

To check the content of a foaming agent the polystyrene granules were saturated in the $20 \mathrm{vol} \%$ solution of ethyl acetate in the ethyl alcohol of $96 \%$ concentration. The saturation was as long as three days. Then a certain mass of polystyrene was placed for three hours in the forvacuum chamber of $110 \pm 10 \mathrm{C}$. The mass difference was shown to be $5 \%$.

The accuracy of the measurements by electronic scales was $10^{-3} \mathrm{~g}$. The quantities of polystyrene measured lay within $2-2.5 \mathrm{~g}$.

The inner-structure non-uniformity (gas bubble's presence) of polystyrene granules is important. This is why the percentage of the so called faulty granules was analyzed for the delivered massifs.

The fraction of $0.5 \pm 0.0025 \mathrm{~mm}$ has no more than $15 \%$ of faulty granules.

The fraction of $0.6 \pm 0.004 \mathrm{~mm}$ has no more than $30 \%$ of faulty granules.

During the $12^{\text {th }}$ quarter the experiments of the ballistic furnace consumed 11 deliveries of the polystyrene granules synthesized and saturated in our group. Part of deliveries were characterized by the Characterization group (Gromov A.I.) The data about the initial particles are included in the report on the ballistic furnace.

\subsubsection{The influence of the thermal fields inside the furnace on the processes of large polystyrene shell formation (sizes of $2 \mathrm{~mm}$ and above).}

A scheme of our installation is shown on Fig. 1. After the modification of the furnace in 1996 the experiments on obtaining the shell sizes of $2 \mathrm{~mm}$ and more. ${ }^{*} \mathrm{~T}$ - Thermocouples are designated. Additional thermocouples were added in the $12^{\text {th }}$ quarter. They are located so that values of temperature on the entrances and exits of each section of a hot zone were known.

Working with saturated fractions of $0.5 \mathrm{~mm}, 0.63 \mathrm{~mm}, 0.7 \mathrm{~mm}$, and $0.8 \mathrm{~mm}$ showed that the yield of thin shells depends on thermal profile on the input of hot zone. The surface quality of the shells formed is dependant on temperature profile near the output of the hot zone. We have three controlled sections of the furnace, so the range of experiments can be wide.

All the experiments were conducted with spherical polystyrene particles saturated with ethyl acetate (mass concentration of $6 \%$ ). The pressure in the furnace was $0.1 \mathrm{~atm}$, atmosphere composition - 50\% $\mathrm{Ar}$ and 50\% He. The diameters of polystyrene granules were 0.7 and $0.8 \mathrm{~mm}$. The massifs of 
polystyrene of $170 \pm 10$ granules were prepared in advance. These granules were thrown through the furnace (run) and counted on the exit. We differ between:

a) unchanged granules

b) symmetric foam spheres

c) non-symmetric foam spheres

d) microspheres formed .

The results are presented in the following tables. They show the relation for the particles of a certain type to the total amount of particles obtained on the output. Each run was repeated no less than tree times. The tables give the average value. The accuracy of the values obtained is defined by the precision of the counting the particles after the run. It lies within 15 up to $25 \%$.

Influence of a temperature profile at the entrance site of a hot zone on the foaming process.

These experiments were conducted with the heated first section of a hot zone $(0.5 \mathrm{~m})$. Thus we had an opportunity to observe the initial stage of a boiling process. With various temperature modes the particles of three types were obtained: a) Particles remaining without changes, b) Non spherical foam particles, c) Spherical foam particles.

A. The content of each type of particles in dependence on temperature of a hot zone (* T3 fig. 1) is shown in the table. Initial size of particles $2 \mathrm{Rs}-0.7+$ $0.015 \mathrm{~mm}$.

$$
\text { Temperature }{ }^{\circ} \mathrm{C} \quad 600 \quad 650 \quad 700 \quad 750 \quad 800 \quad 850 \quad 900
$$

$1 \quad$ Particles

remaining

without

$\begin{array}{lllllll}0.65 & 0.5 & 0.4 & 0.15 & 0.05 & 0.05 & -\end{array}$

changes.

2 Non spherical

foam particles.

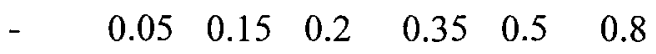

3 Spherical

$\begin{array}{lllllll}0.35 & 0.45 & 0.45 & 0.65 & 0.6 & 0.45 & 0.2\end{array}$

foam particles.

The other conditions: the accuracy of $\mathrm{T}_{3}$ is $\mathrm{I}_{3} \pm 10 \mathrm{C}$, temperature $\mathrm{T}_{1}=400 \pm 10 \mathrm{C}$.

We regard $\mathrm{T}=800 \mathrm{C}$ to be an optimum temperature of foaming process. 
The influence of initial temperature gradient on the boiling process is presented in this table:

\begin{tabular}{|c|c|c|c|c|c|c|c|}
\hline \multirow{3}{*}{1} & $\mathrm{dT} / \mathrm{dx}{ }^{\circ} \mathrm{C} / \mathrm{M}$ & 400 & 800 & 1200 & 1600 & 2000 & 2400 \\
\hline & Particles & & & & & & \\
\hline & remaining & 0.05 & 0.05 & 0.05 & 0.1 & 0.1 & 0.15 \\
\hline & $\begin{array}{l}\text { Without } \\
\text { changes. }\end{array}$ & & & & & & \\
\hline 2 & Non spherical & & & & & & \\
\hline & foam & 0.55 & 0.45 & 0.4 & 0.4 & 0.55 & 0.6 \\
\hline & particles & & & & & & \\
\hline 3 & Spherical & & & & & & \\
\hline & $\begin{array}{l}\text { foam } \\
\text { particles. }\end{array}$ & 0.4 & 0.5 & 0.55 & 0.5 & 0.35 & \\
\hline
\end{tabular}

Content of each type of particles in dependence on a gradient of temperature on the entrance of a hot zone (( T3-TI ) / $0.25 \mathrm{~m}$ see Fig. 1). Temperature of the hot zone is $800 \mathrm{C} . \mathrm{T}_{1}=(200 \mathrm{C} ; 700 \mathrm{C})$. Initial granules diameters are $0.7 \pm 0.005 \mathrm{~mm}$.

The results obtained show the yield of symmetric spherical foam particles to reach its maximum within the temperature range 400-600 C.

During the study of initial stage of foaming process in various thermal conditions the inner structure of the foam spheres was investigated together with characterization group leaded by Gromov A.I. These studics resulted in a paper of multi-nuclei formation (see above).

\subsubsection{Monoshells formation processes.}

Dependence of the content of each type of: a) spherical monoshells; b) spherical foam particles; c) nonspherical foam particles; d) particles remaining without changes on temperature of a hot zone (TI-T2-T3=T4 see fig. 1).

\begin{tabular}{|c|c|c|c|c|c|c|c|c|}
\hline \multirow[b]{2}{*}{1} & $\mathrm{~T}^{\circ} \mathrm{C}$ & 600 & 650 & 700 & 750 & 800 & 850 & 900 \\
\hline & $\begin{array}{l}\text { Particles } \\
\text { remaining } \\
\text { unchanged }\end{array}$ & 0.2 & 0.15 & 0.05 & 0.05 & -0 & - & - \\
\hline \multirow[t]{2}{*}{2} & $\begin{array}{l}\text { Nonspherical } \\
\text { foam particles }\end{array}$ & 0.3 & 0.35 & 0.4 & 0.4 & 0.4 & 0.4 & 0.35 \\
\hline & $\begin{array}{l}\text { Spherical foam } \\
\text { 'particles }\end{array}$ & 0.4 & 0.35 & 0.3 & 0.2 & 0.15 & 0.05 & - \\
\hline 3 & $\begin{array}{l}\text { Spherical } \\
\text { monoshells }\end{array}$ & 0.1 & 0.15 & 0.25 & 0.35 & 0.45 & 0.55 & 0.65 \\
\hline
\end{tabular}




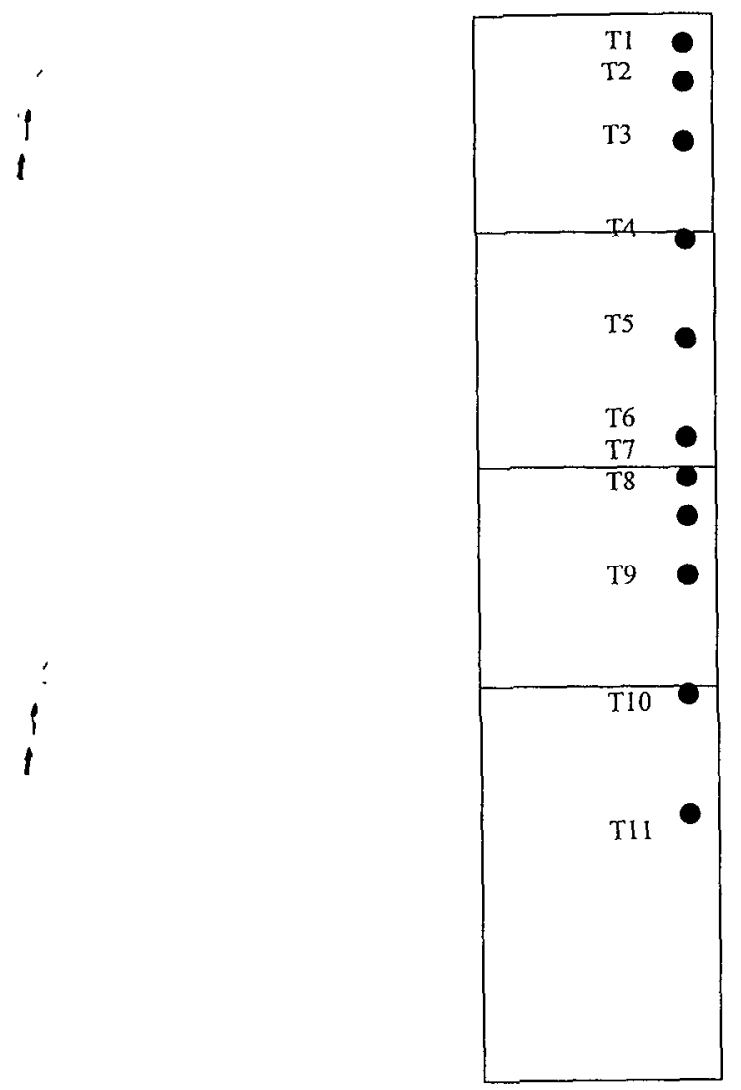

' Рис. 1.

1

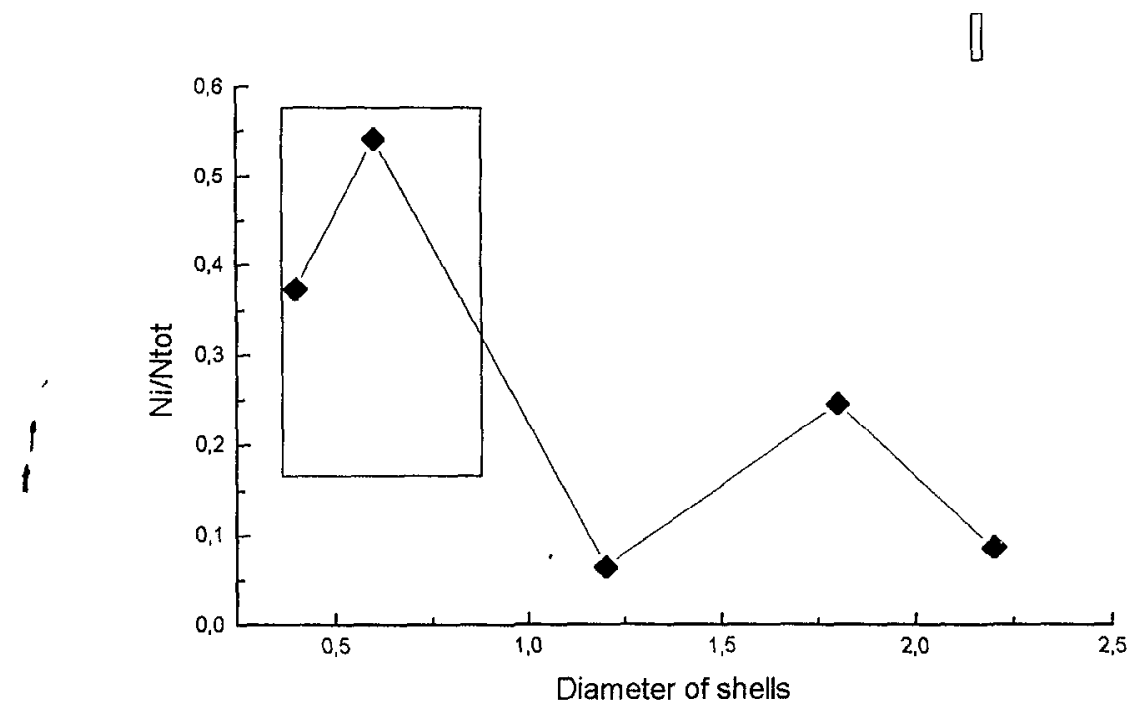

Рис. 2. 
$\mathrm{T}=850 \mathrm{C}-$ temperature, at which "condition of explosion" occurred. Other conditions: $\mathrm{T}_{3}=\mathrm{T}_{4}=\mathrm{T}_{5}=\mathrm{T}_{6}$.

Distribution function of monoshells by size in "condition of explosion" is presented on Fig. 2. ( $\mathrm{T}=800^{\circ} \mathrm{C}, 2 \mathrm{R} \approx 0.7 \mathrm{~mm}$, length of the hot zone is $1 \mathrm{~m}$ ).

\subsubsection{Influence of a temperature profile at the exit from hot zone on the quality of a surface of shells.}

Distribution function of monoshells by sizes at $\mathrm{T}=800^{\circ} \mathrm{C}$. The size of initial particles are $0.7 \mathrm{~mm}$. Length of a hot zone is $1 \mathrm{~m}$.

Fig. 3. Part of quality microspheres in relation to total number of monoshells. $\mathrm{T}=800^{\circ} \mathrm{C}$, size of initial particles $-0.7 \mathrm{~mm}$, length of the hot zone is $1 \mathrm{~m}$.

Figure 4 shows the influence of temperature gradient in the exit of hot zone on the quantity of quality microspheres at $\mathrm{T}-800 \mathrm{C}$, length of the hot zone $1 \mathrm{~m}$. At transition from initial particles $2 \mathrm{R}=0.7 \pm 0.005 \mathrm{~mm}$ to particles $2 \mathrm{R}=0.8 \pm 0.006 \mathrm{~mm}$ the output of quality shells decreases, the range of appropriate gradients becomes narrower.

\subsection{Conclusions.}

The studies carried out have shown, that the temperature gradients on the entrance and the exit of a hot zone influence essentially the processes of formation of large (from 1.8 up to $3 \mathrm{~mm}$ ) good quality surface polystyrene shells. 


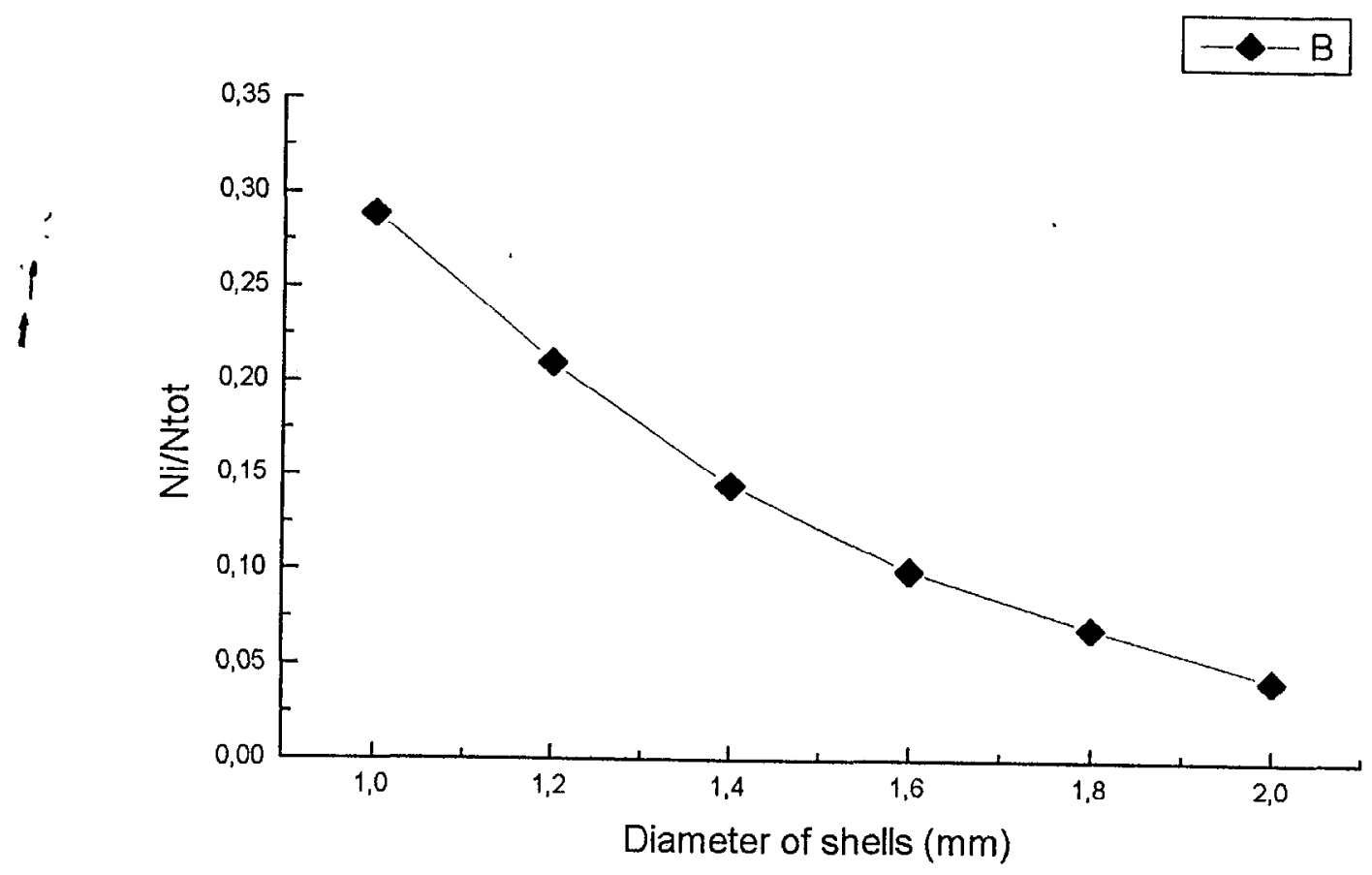

Pис.3.

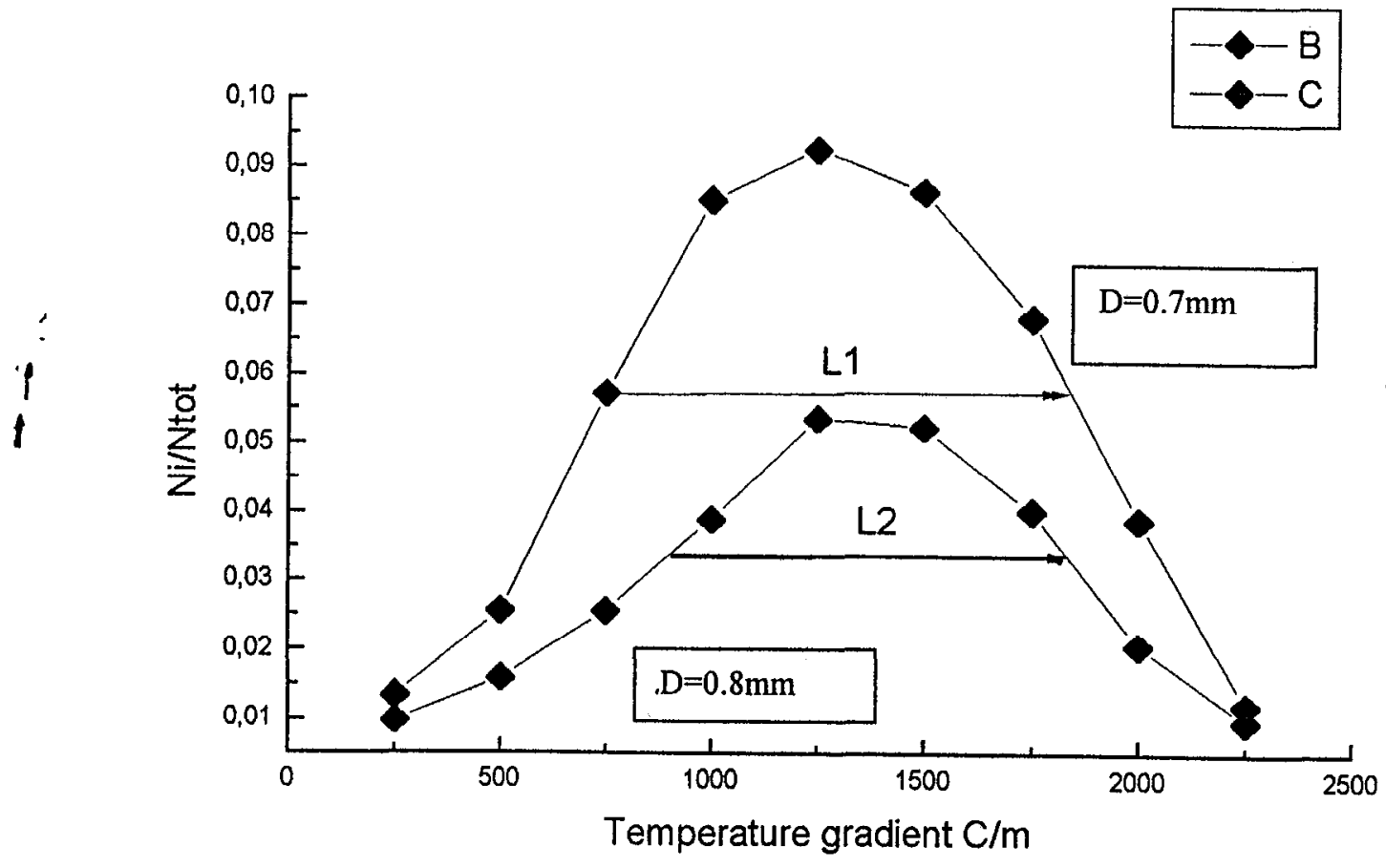

Рис.4. 
In the twelfth quarter some improvements have been fulfilled in the complex of simulating programs.

The program for preparation of initial data (STARINI) was essentially improved. Two new ASCII files were introduced:

1. for destructive gas data,

2. for data controlling heat sources due to polymer decomposition and evaporation of gas-foamer and destructive gas from outer surface.

Besides, the interface to introduce necessary data was remade. Now this operation became easier. The example of registration file is presented in fig. 1 .

Also we modernized the main program (STARMOV). There was introduced possibility of shell cooling due to gas-foamer evaporation from outer surface. Heat flow from outer surface is proportional to mass flow of gasfoamer:

$$
\frac{d Q}{d t}=-\left.k_{v o l}^{(1)} \cdot \frac{d M}{d t}\right|_{r=r_{o}}
$$

where $k_{v o l}^{(1)}=E_{1}\left(1-\frac{T}{T_{1}}\right)+E_{2}\left(1-\frac{T}{T_{2}}\right), T$ is temperature. Coefficients $E_{1}, E_{2}$ and crytical temperatures $T_{1}, T_{2}$ depend on matter of gas-foamer. We take into consideration in our calculations two substances as gas-foamer: water and ethylacetat. The table 1 shows the constants for these substances.

Table 1

$\begin{array}{ccccc}\text { Substance } & E_{1}, \mathrm{~J} / \mathrm{kg} & E_{2}, \mathrm{~J} / \mathrm{kg} & T_{1}, \mathrm{~K} & T_{2}, \mathrm{~K} \\ \text { Water } & 4.0 \cdot 10^{6} & 0.7 \cdot 10^{6} & 523 & 657 \\ \text { Ethylacetat } & 0.8 \cdot 10^{6} & 0.2 \cdot 10^{6} & 1000 & 1000\end{array}$

Besides, these constants can be considered as free parameters and selected from comparison with experimental data. The results of simulating are shown in figs. $2-5$. These figures show dependencies of radius on coordinate in furnace $\mathrm{z}$ for gases-foamers from table 1 . Oversaturation $S$ has values 20,40 , and 60 . The figs. 2 and 4 show results with coefficients $E_{1}$ and $E_{2}$ being got from table 1 . The figs. 3 and 5 show results with coefficients $E_{1}$ and $E_{2}$ multiplying by 10 . It is visible that values $E_{1}$ and $E_{2}$ do not influence the simulating results. Other dependencies that we can construct do not change also.

In fig. 6 shown are the results of modeling with large oversaturation $S$ (ethylacetat). 
Pressure in Furnace $=2.00000 \mathrm{E}+04 \mathrm{~Pa}$

Number of Temperature Points $=5$

Coordinates $(m)$ of Points $\left(1, \ldots, N_{-}\right.$Temp_Points $)$

$\begin{array}{lllll}.0 & .1 & 1.0 & 1.5 & 2.0\end{array}$

Temperatures (K) At Points $\left(1, \ldots, N_{-}\right.$Temp_Points)

300.01000 .01000 .0500 .0300 .0

Gas - Foamer Data

$\mathrm{MU}(\mathrm{kg} / \mathrm{kmol})=18.000$ Solvency $(\mathrm{s} * * 2 / \mathrm{m} * * 2)=1.00000 \mathrm{E}-05$

Diffusion Coefficient $\left(\mathrm{m}^{* *} 2 / \mathrm{s}\right)=1.00000 \mathrm{E}-06 \mathrm{ED}(\mathrm{K})=3.54000 \mathrm{E}+03$

Gas in Furnace Data

$\mathrm{MU}(\mathrm{kg} / \mathrm{kmol})=40.000$ Density $\left(\mathrm{kg} / \mathrm{m}^{* *} 3\right)=1.73000 \mathrm{E}+00$

Viscosity $(\mathrm{Pa} \mathrm{s})=1.85000 \mathrm{E}-05 \mathrm{Cvis}(\mathrm{K})=8.30000 \mathrm{E}+01$

Heat Coefficient $(\mathrm{W} /(\mathrm{m} \mathrm{K}))=1.43000 \mathrm{E}-01$ Index $=7.06000 \mathrm{E}-01$

Diffusion Coefficient $\left(\mathrm{m}^{* *} 2 / \mathrm{s}\right)=1.00000 \mathrm{E}-06 \mathrm{ED}(\mathrm{K})=3.75000 \mathrm{E}+03$

Solvency $\left(\mathrm{s}^{* *} 2 / \mathrm{m}^{* *} 2\right)=2.00000 \mathrm{E}-07$

Destructive Gas

$\mathrm{MU}(\mathrm{kg} / \mathrm{kmol})=72.000$ Solvency $\left(\mathrm{s}^{* *} 2 / \mathrm{m}^{* *} 2\right)=3.40000 \mathrm{E}-06$

Diffusion Coefficient $\left(\mathrm{m}^{* *} 2 / \mathrm{s}\right)=1.00000 \mathrm{E}-06 \mathrm{ED}(\mathrm{K})=3.45000 \mathrm{E}+03$

Droplet Data

Initial Radius $(\mathrm{m})=3.50000 \mathrm{E}-04$ Initial Coordinate $(\mathrm{m})=0.00000 \mathrm{E}+00$

Initial Velosity $(\mathrm{m} / \mathrm{s})=0.00000 \mathrm{E}+00$ Initial Temperature $(\mathrm{K})=3.30000 \mathrm{E}+02$

Heat Coefficient $=8.00000 \mathrm{E}-02$ Density $\left(\mathrm{kg} / \mathrm{m}^{* *} 3\right)=9.00000 \mathrm{E}+02$

$\mathrm{Cp}(\mathrm{J} /(\mathrm{kg} \mathrm{K}))=3.00000 \mathrm{E}+03$ Surface Tension $(\mathrm{N} / \mathrm{m})=2.00000 \mathrm{E}-02$

Viscosity Coefficient $(\mathrm{Pa} \mathrm{s})=3.00000 \mathrm{E}+00 \mathrm{E}(\mathrm{K})=6.21000 \mathrm{~F}+16$

Limit Stress of Momentary Break $(\mathrm{Pa})=1.30000 \mathrm{E}+08$

Oversaturation $=6.20000 \mathrm{E}+01$

Initial Inner Radius/Initial Radius $=5.00000 \mathrm{E}-03$

Some Parameters To Adjust

Fst Coef. for Evap. Formula of Gas-Foamer $(\mathrm{J} / \mathrm{kg})=.40000 \mathrm{E}+07$

Snd Coef. for Evap. Formula of Gas-Foamer $(\mathrm{J} / \mathrm{kg})=.70000 \mathrm{E}+06$

Fst Crit. Temp. for Evap. Fmla of Gas-Foamer $(\mathrm{K})=.65700 \mathrm{E}+03$

Snd Crit. Temp. for Evap. Fmla of Gas-Foamer $(\mathrm{K})=.10000 \mathrm{E}+04$

Heat Evap. Coeff. of Destr. Gas (J/kg) $=.13000 \mathrm{E}+09$

Heat Of Polymer Destruction $(\mathrm{J} / \mathrm{kg})=.26000 \mathrm{E}+10$

Radiation Coeff. $(\mathrm{J} /(\mathrm{kg} \mathrm{s}))=.10000 \mathrm{E}+04$

Fig. 1. Example of new registration file. 
Ethylacetath

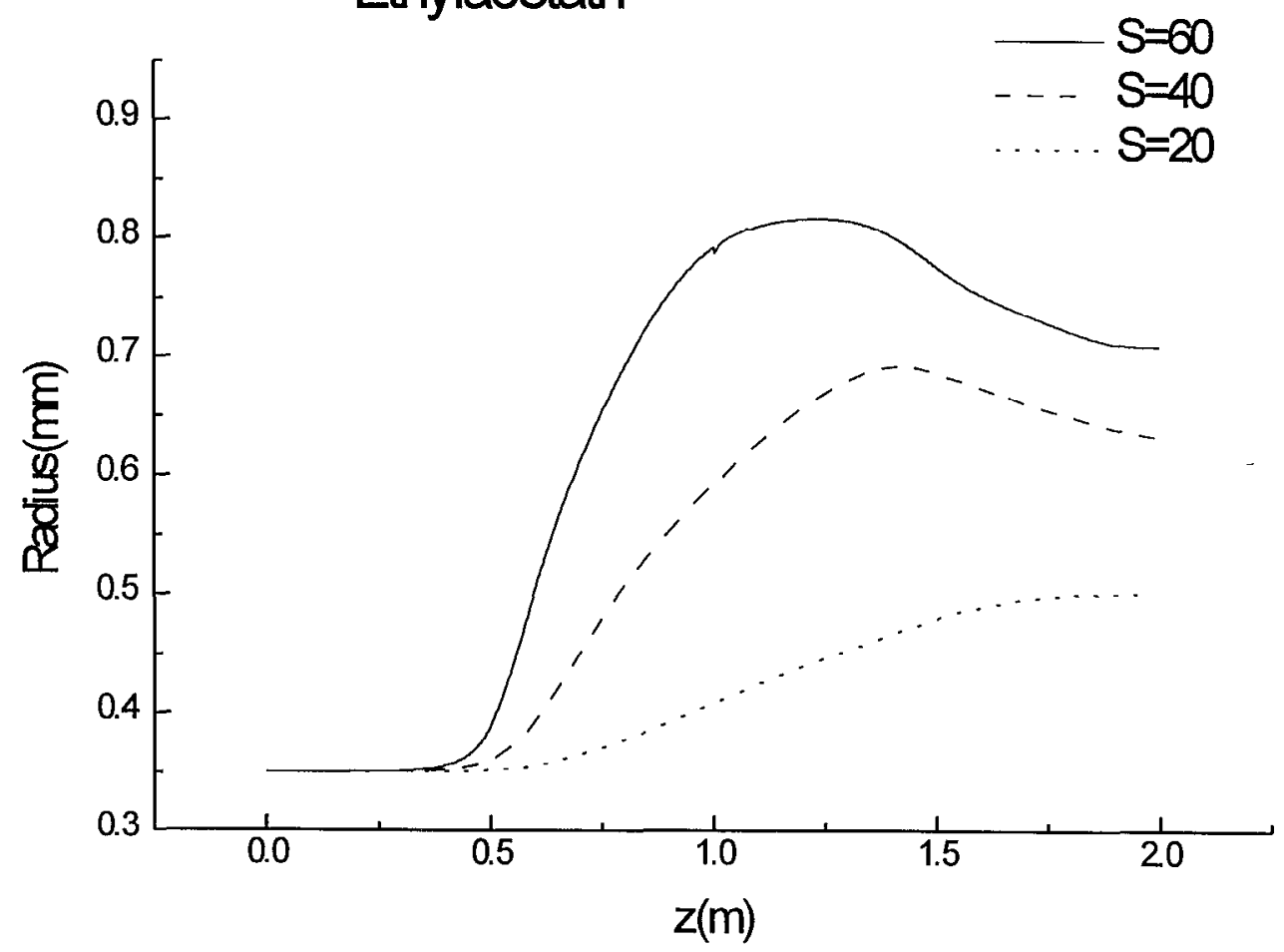

Fig. 2. Ethylacetath, coefficients $E_{1}$ and $E_{2}$ have table values.

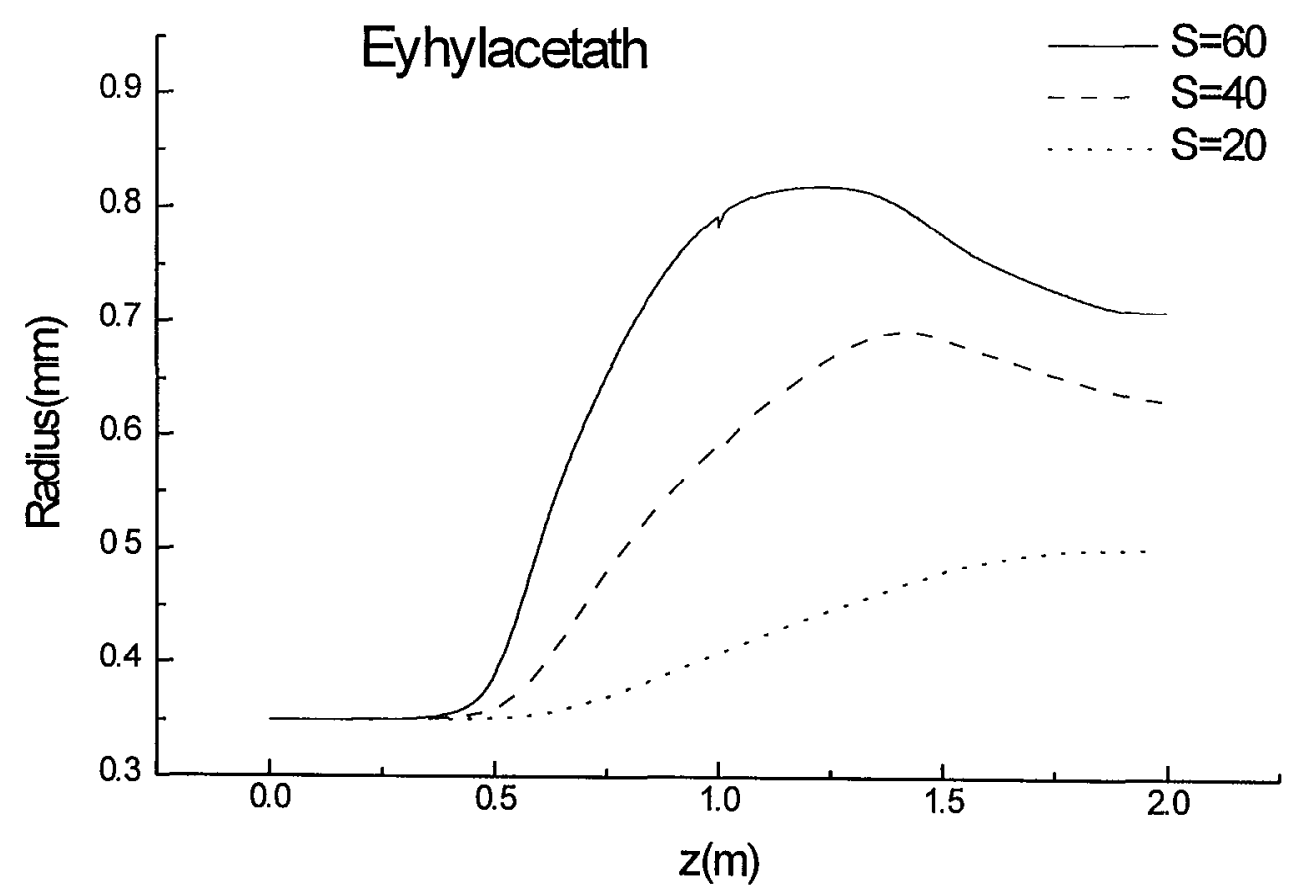

Fig. 3. Ethylacetath, coefficients $E_{1}$ and $E_{2}$ have table values multiplying by 10 . 


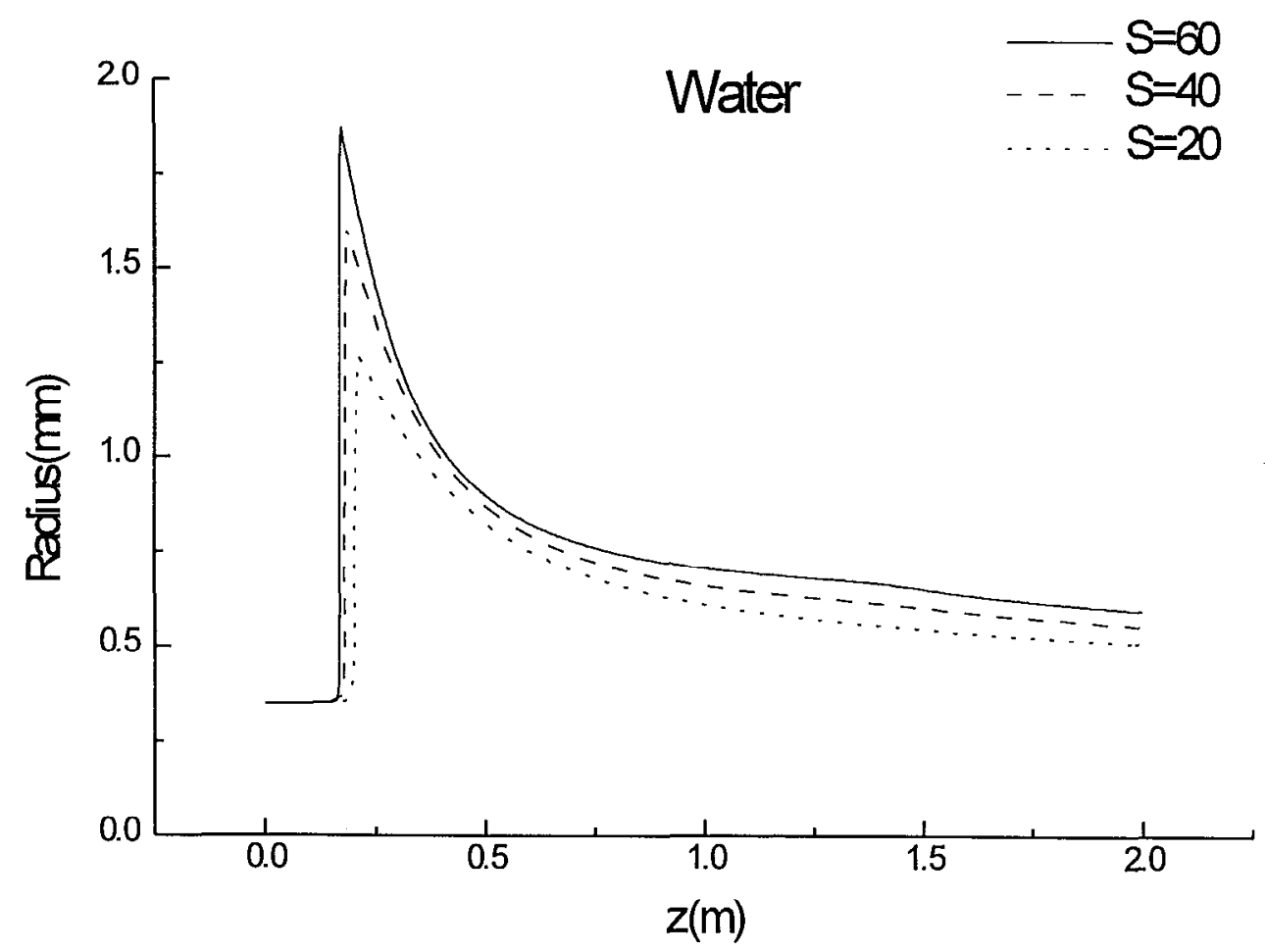

Fig. 4. Water, coefficients $E_{1}$ and $E_{2}$ have table values.

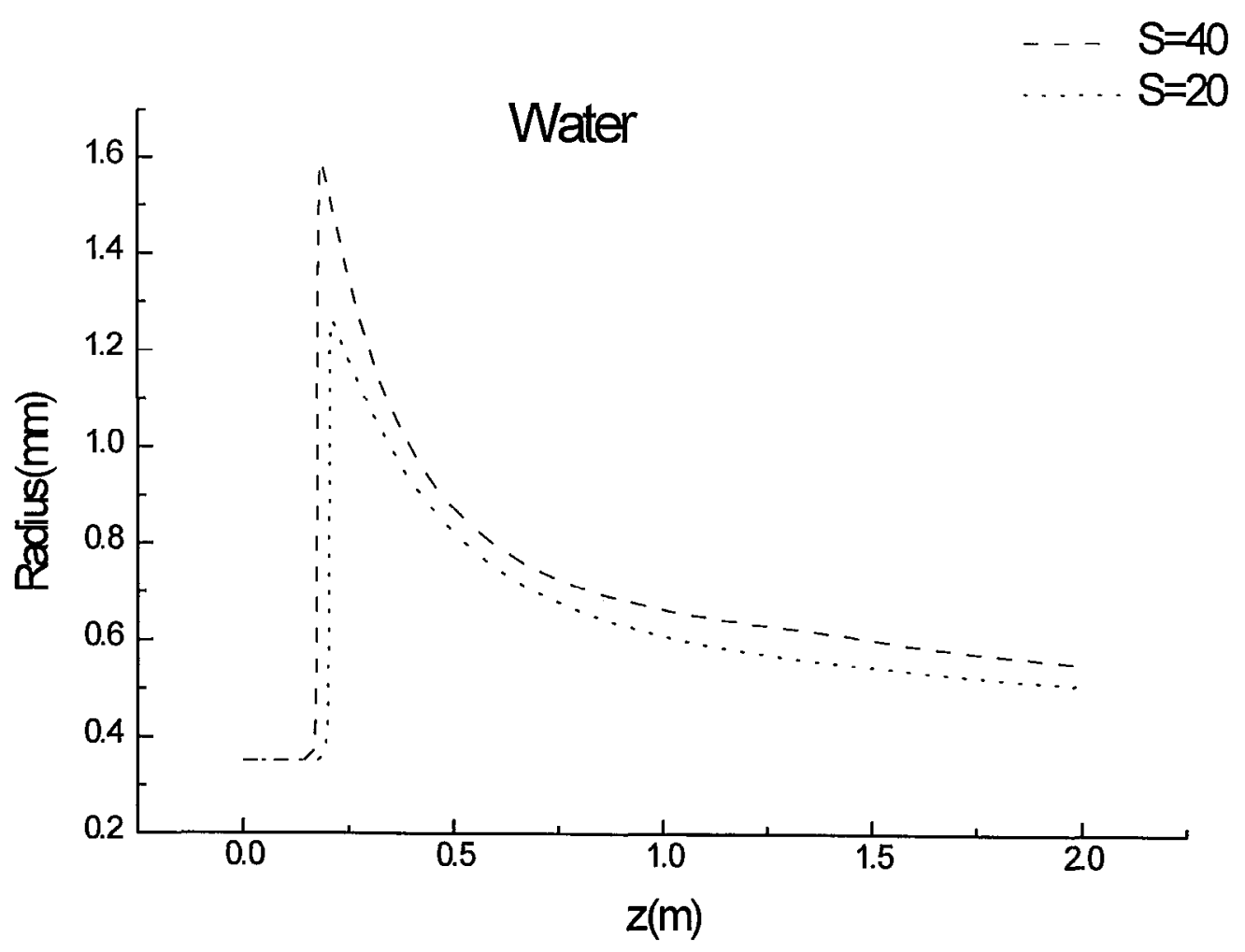

Fig. 5. Water, coefficients $E_{1}$ and $E_{2}$ have table values multiplying by 10 . 


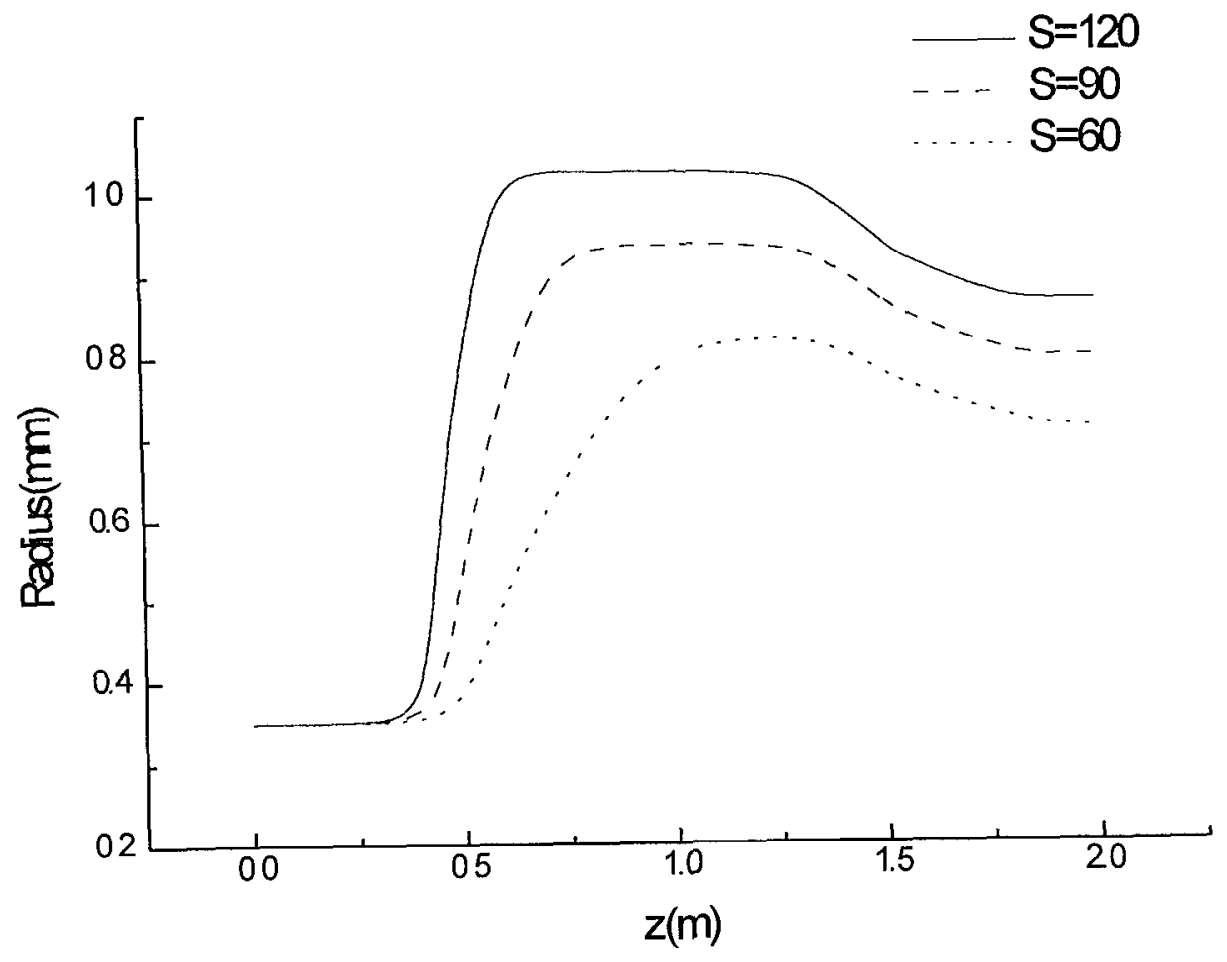

Fig.6. 


\section{Conclusion}

The optimum regime of polystyrene shell formation is defined. The temperature, gas pressure, and atmosphere composition are found for the Ballistic furnace with hot zone of 1 meter height.

\section{Experimental results:}

- large set of experiments with 0.71-0.8 mm narrow size distribution initial granules was carried out and stable shells fabrication regimes for some granules fractions were found.

- it was confirmed that final sizes of formed shells weakly depends on operational conditions.

- complete set of experimental results with allowance for new data had shown qualitatively coincidence with model calculations.

-scaling for size of shells produced with $1.5 \mathrm{~m}$ hot zone had been made based on complete expcrimental data and extended modeling calculations. It shows opportunity of $2 \mathrm{~mm}$ shells production with upgraded ballistic furnace.

1. Technical itcms:

- improved technique for granules separation had been developed and used in the last experiments.

- precision electronic equipment for tempcrature monitoring had been made, adjusted and put into operation.

- half-length hot zone had been manufactured and assembled.

- new cooling zone with water cooling had been manufactured and tested.

In the near future we are going to make ballistic furnace upgrade. We have stopped current experiments with the ballistic furnace now and started to prepare installation for upgrading. As things go we hope to continue experiments with the new ballistic furnace in early autumn.

Many shells' formation experiments were carried out and results of these experiments were compared with theoretical calculations. But this experiments were carried out with initial granules contained 3.5\% (weight) of blowing agents (ethyl acetate, water, monomer etc.). New experiments on drop tower furnace had goal to research dependence of shell diameter from quantity of blowing agents. Besides that on drop tower furnace dependence of large (about $2 \mathrm{~mm}$ ) shell surface quality from temperature profiles were researched.

At $12^{\text {th }}$ quarter computer program improvements, which helped user introduce of physical constants and technological conditions, were carried. Besides that in model and computer codes were included new physical processes. We begin to take into account energy of boiling and energy of connection between boiling agent and polymer on surface of polymer shells. 


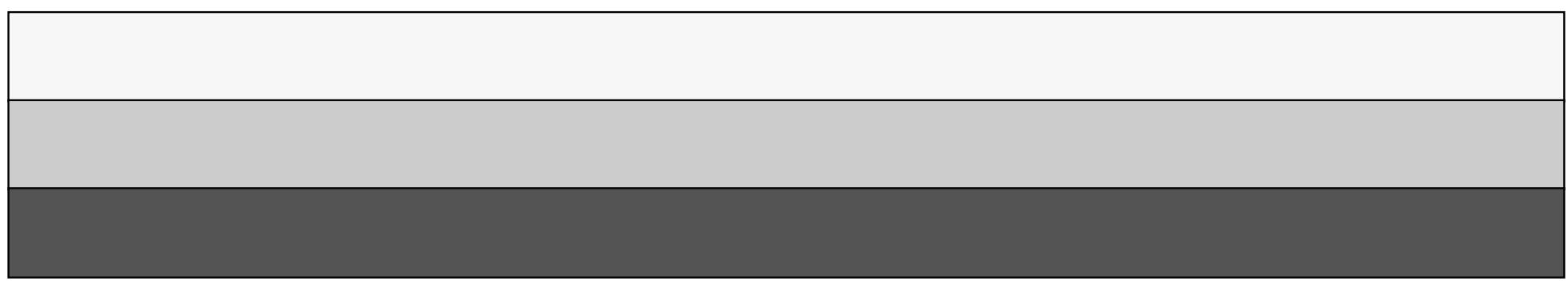

